\title{
Article \\ System-Analytical Method of Earthquake-Prone Areas Recognition
}

\author{
Boris A. Dzeboev ${ }^{1,2, *(0)}$, Alexei D. Gvishiani ${ }^{1,3}$, Sergey M. Agayan ${ }^{1}$, Ivan O. Belov ${ }^{1}$, Jon K. Karapetyan ${ }^{1,4}($, \\ Boris V. Dzeranov ${ }^{1,2}$ and Yuliya V. Barykina ${ }^{1}$ \\ 1 Geophysical Center of the Russian Academy of Sciences (GC RAS), 119296 Moscow, Russia; \\ adg@wdcb.ru (A.D.G.); s.agayan@gcras.ru (S.M.A.); i.belov@gcras.ru (I.O.B.); jon_iges@mail.ru (J.K.K.); \\ b.dzeranov@gcras.ru (B.V.D.); u.barykina@gcras.ru (Y.V.B.) \\ 2 Geophysical Institute (GPI VSC RAS), Vladikavkaz Scientific Center RAS, 362002 Vladikavkaz, Russia \\ 3 Schmidt Institute of Physics of the Earth of the Russian Academy of Sciences (IPE RAS), \\ 119296 Moscow, Russia \\ 4 Institute of Geophysics and Engineering Seismology after A. Nazarov (IGES NAS RA), Gyumri 3115, Armenia \\ * Correspondence: b.dzeboev@gcras.ru; Tel.: +7-495-930-05-46
}

Citation: Dzeboev, B.A.; Gvishiani, A.D.; Agayan, S.M.; Belov, I.O.;

Karapetyan, J.K.; Dzeranov, B.V.; Barykina, Y.V. System-Analytical Method of Earthquake-Prone Areas Recognition. Appl. Sci. 2021, 11, 7972. https://doi.org/10.3390/app11177972

Academic Editor: Giuseppe Lacidogna

Received: 30 July 2021

Accepted: 26 August 2021

Published: 28 August 2021

Publisher's Note: MDPI stays neutral with regard to jurisdictional claims in published maps and institutional affiliations.

Copyright: (c) 2021 by the authors. Licensee MDPI, Basel, Switzerland. This article is an open access article distributed under the terms and conditions of the Creative Commons Attribution (CC BY) license (https:/ / creativecommons.org/licenses/by/ $4.0 /)$.

\begin{abstract}
Typically, strong earthquakes do not occur over the entire territory of the seismically active region. Recognition of areas where they may occur is a critical step in seismic hazard assessment studies. For half a century, the Earthquake-Prone Areas (EPA) approach, developed by the famous Soviet academicians I.M. Gelfand and V.I. Keilis-Borok, was used to recognize areas prone to strong earthquakes. For the modern development of ideas that form the basis of the EPA method, new mathematical methods of pattern recognition are proposed. They were developed by the authors to overcome the difficulties that arise today when using the EPA approach in its classic version. So, firstly, a scheme for the recognition of high seismicity disjunctive nodes and the vicinities of axis intersections of the morphostructural lineaments was created with only one high seismicity learning class. Secondly, the system-analytical method FCAZ (Formalized Clustering and Zoning) has been developed. It uses the epicenters of fairly weak earthquakes as recognition objects. This makes it possible to develop the recognition result of areas prone to strong earthquakes after the appearance of epicenters of new weak earthquakes and, thereby, to repeatedly correct the results over time. It is shown that the creation of the FCAZ method for the first time made it possible to consider the classical problem of earthquake-prone areas recognition from the point of view of advanced systems analysis. The new mathematical recognition methods proposed in the article have made it possible to successfully identify earthquake-prone areas on the continents of North and South America, Eurasia, and in the subduction zones of the Pacific Rim.
\end{abstract}

Keywords: system-analytical method; earthquake-prone areas; pattern recognition; clustering; machine learning; earthquake catalogs; high seismicity criteria

\section{Introduction}

As a rule, strong earthquakes may not occur over the entire territory of a seismically active region. Critical objectives of the seismic hazard assessment include recognition of the areas prone to strong earthquakes. An effective instrument to accomplish this objective is pattern recognition. The fundamental possibility of employment methods and algorithms for pattern recognition to identify potentially high seismicity areas was first substantiated by remarkable mathematician I.M. Gelfand et al. in 1972 [1,2]. The developed approach was later called EPA (Earthquake-Prone Areas) [3-7].

The EPA method was developed in the fundamental papers of I.M. Gelfand and V.I. Keilis-Borok, members of the Academy of Sciences of the USSR; A.D. Gvishiani, academician of the RAS; Al.An. Soloviev, associate member of the RAS; and famous Soviet and Russian scientists, namely Sh.A. Guberman, M.P. Zhidkov, V.G. Kossobokov, A.I. Gorshkov, 
V.A. Gurvich, E.Ya. Rantsman, I.M. Rotvain, etc. Prominent foreign geophysicists, seismologists, geologists, and mathematicians took an active part in developing EPA. These include F. Press and L. Knopoff, members of the United States National Academy of Sciences; Professors A. Cisternas, J. Bonnin, E. Philip, C. Weber, and J. Sallantin, French scientists; as well as M. Caputo and G. Panza, members of the National Academy of Sciences of Italy, etc. [5-7].

In the classical Gelfand-Keilis-Borok setting, the problem of strong earthquake-prone areas recognition (EPA problem) is formulated as follows. In a considered seismically active region, it is necessary to recognize the areas prone to strong earthquakes (with magnitude $M \geq M_{0}$, where $M_{0}$ is a given threshold). These areas are sought among the recognition objects identified in the region. As the recognition objects, morphostructural nodes or intersections of morphostructural lineaments obtained as a result of morphostructural zoning (MSZ) of the region are considered [8-12]. It is necessary to divide the set of recognition objects $W$ into two non-intersecting classes: class $B$ consisting of the objects whose vicinities are prone to strong earthquakes and class $H$, which is composed of the objects where such earthquakes cannot occur.

This classification is carried out with the employment of the pattern recognition algorithm with learning. It uses the learning set $W_{0}$, which is determined based on the information about the seismicity of the region. In turn, $W_{0}$ consists of two non-intersecting subsets $B_{0}$, containing objects that are a priori referred to as class $B$, and $H_{0}$, containing the representatives of class $H$. The result of applying the recognition algorithm is a decision function based on which an object from $W$ can be attributed to class $B$ or $H$, and the classification of the objects itself [4-6].

A detailed literary review for almost half a century of the development and application of pattern recognition algorithms to solve the recognition problem of areas prone to strong earthquakes (EPA approach), carried out by the authors of this article, is given in [5]. This paper examines the applied pattern recognition algorithms, the studied regions, and methods for assessing the reliability of the results obtained, including the theory of dynamic and limit recognition problems. This work is devoted to the presentation of modern mathematical methods developed at the Geophysical Center of the Russian Academy of Sciences, aimed at overcoming the difficulties that may arise today when using the EPA approach in its classic 50-year version. In the present paper, the problem of earthquake-prone areas recognition is considered in the classical formulation of GelfandKeilis-Borok.

Talking about the drawbacks of the EPA method, the following should be noted. The formation of learning material is a fundamental phase of recognition. Learning set $B_{0}$ includes the objects with known epicenters of strong earthquakes in the vicinities. It is reasonable to assume that set $B_{0}$ formed in this way is highly likely to contain no a priori errors or so few of them that they are unable to affect significantly the recognition result. It is hard to form a similar "clean" learning material of class $H$. The set $H_{0}$ contains either all objects not included in $B_{0}$ or objects with known earthquakes with magnitude $M<M_{0}-\delta$, where $\delta>0[5,13]$ in the vicinities.

As regards the essence of the EPA problem, which represents a threshold problem of recognition $[4,14,15]$, learning class $H_{0}$ entails inherent potential errors. Accordingly, a low seismicity learning class is not at all a totality of benchmark objects that cannot be related to strong earthquake-prone areas. Learning sets $B_{0}$ and $H_{0}$ turn out to be disparate [16,17], and the EPA procedure ignores this fact [13].

Many years of applying the EPA method in numerous mountainous countries of the world [5] demonstrated the need to avoid learning asymmetry in recognition. Making EPA findings more reliable necessitates amending the recognition unit by adding a learning algorithm based on the only high seismicity class $B_{0}$, which includes objects with known strong earthquakes in their vicinities [13]. The development of this kind of recognition algorithm has been one of the main objectives of this study. 
Another drawback of the EPA method is that the identification of recognition objects and the measurement of their geological-geophysical and geomorphologic characteristics is a time- and effort-consuming problem. That said, the possibility of using selected objects needs separate justification for every region [5]. The foregoing illustrates that the practical employment of the EPA method is still challenging to a great extent. This forced the authors to develop new state-of-the-art algorithmic systems, which enable the automation of the recognition process. The key objective of study was to set up and develop this kind of system.

\section{Materials and Methods}

\subsection{Recognition of the Areas Prone to Strong Earthquakes with One Learning Class}

In the papers [4,5], the EPA approach was further developed by creating a new algorithm called Barrier-3, employed in the recognition unit $[13,16,17]$. It should be especially noted that the principal difference of the Barrier-3 algorithm from the dichotomy algorithms previously used in EPA is that learning is based only on $B_{0}$ high seismicity class set.

Broadly speaking, the Barrier-3 algorithm, which learns based only on one class, is not a dichotomy algorithm. However, it can be used in the EPA. Barrier-3 also divides the territory into two non-intersecting areas that are either prone or not prone to strong earthquakes.

Similarly, to the dichotomy algorithms [5], the Barrier-3 algorithm views disjunctive nodes or axis intersections of the morphostructural lineaments as recognition objects. Such selection of objects derives from their deep tectonic connection with strong earthquakes. The confinedness of the strong earthquake epicenters to the intersections of morphostructural lineaments was statistically confirmed in the paper [18].

The objective of the Barrier-3 algorithm is to study the characteristics of learning set $B_{0}$ of the only high seismicity class and identify the objects that are "similar" to the learning objects based on the knowledge obtained. The latter are declared as high seismicity ones. Speaking the language of the theory of sets, Barrier-3 accomplishes the objective of constructing in the finite set of objects $W$ and its subset $B$, broadening the only learning class $B_{0}$. For this reason, the disparity measure between two arbitrary objects is constructed for every characteristic. This allows finding and measuring the "barrier," which divides these objects as part of the considered characteristic. This assessment acts as a proximity measure for the initial set $W$, which enables giving exact meaning to the idea of proximity to $B_{0}$ based on a given totality of characteristics. Let us move on to the description of the mathematical construction of the Barrier-3 algorithm $[13,16]$.

Let us assume that $\Pi=\{\pi\}$ is a finite totality of numerical characteristics of recognition objects $w \in W$, and $\pi: W \rightarrow R, B_{0}$ is own subset in $W$ for learning of high seismicity class $B$. Based on the totality of characteristics $\Pi$ of a set of objects $W$, it is necessary to construct a set $P_{\Pi}\left(B_{0}\right)$ that would adequately expand $B_{0}$ in the sense of requirements of the formulated problem.

The proximity of the objects $w_{1}$ and $w_{2}$ by characteristic $\pi$ is "hampered" by all those objects $w$ whose $\pi(w)$ values lie in between the values $\pi\left(w_{1}\right)$ and $\pi\left(w_{2}\right)$. They make up a barrier:

$$
\mathrm{Б}_{\pi}\left(w_{1}, w_{2}\right)=\left\{w \in W: \min \left(\pi\left(w_{1}\right), \pi\left(w_{2}\right)\right) \leq \pi(w) \leq \max \left(\pi\left(w_{1}\right), \pi\left(w_{2}\right)\right)\right\}
$$

It is natural to assume that the lower the barrier $\mathrm{b}_{\pi}\left(w_{1}, w_{2}\right)$, the better it is for the proximity of $w_{1}$ and $w_{2}$ on $W$ by characteristic $\pi$. This observation explains the name of the algorithm.

Let us call the ratio

$$
\rho_{\pi}\left(w_{1}, w_{2}\right)=\left|\mathrm{Б}_{\pi}\left(w_{1}, w_{2}\right)\right| /|W|
$$

disparity measure between $w_{1}$ and $w_{2}$ by characteristic $\pi$ or simply barrier measure.

The Barrier-3 algorithm forms the set of $P_{\Pi}(v)$ objects that are close to $v \in B_{0}$ from $W$ based on the characteristics $\Pi$ in three phases. 
Phase one: formation of set $P_{\pi}(v)$ of objects that are close to $v$ in $W$ by characteristic $\pi$ using the minimality threshold $\alpha_{\pi}(v)$ :

$$
P_{\pi}(v)=\left\{w \in W: \rho_{\pi}(w, v) \leq \alpha_{\pi}(v)\right\}
$$

The threshold $\alpha_{\pi}(v)$ performs the functions of the flexible lower boundary of the set $\left\{\rho_{\pi}(w, v), w \in W\right\}$ and can be obtained, for example, using Kolmogorov averaging with the value $s<0$ :

$$
\alpha_{\pi}(v)=\left(\frac{\sum_{\bar{w} \in W} \rho_{\pi}(\bar{w}, v)^{s}}{|W|}\right)^{1 / s}
$$

Phase two: formation on $W$ of the value $p_{\Pi}(w \mid v)$ showing the proximity of $w$ to $v$ based on all characteristics $\Pi$ :

$$
p_{\Pi}(w \mid v)=\left|\left\{\pi \in \Pi: w \in P_{\pi}(v)\right\}\right| .
$$

Here $P_{\pi}(v)$ is determined by the formula (3), and the integral exponent $p_{\Pi}(w \mid v)$ introduced by the formula (5) varies from 0 to $|\Pi|$.

Phase three: formation in $W$ of a subset of $P_{\Pi}(v)$ objects that are close to $v$ based on all characteristics $\Pi$ using the maximality threshold $\beta_{\Pi}(v)$ :

$$
P_{\Pi}(v)=\left\{w \in W: p_{\Pi}(w \mid v) \geq \beta_{\Pi}(v)\right\}
$$

The threshold $\beta_{\Pi}(v)$ performs the functions of flexible upper boundary of the set of values $\left\{p_{\Pi}(w \mid v), w \in W\right\}$. Similarly, to the formula (4), $\beta_{\Pi}(v)$ can be constructed using Kolmogorov averaging with the value $q>0$ :

$$
\beta_{\Pi}(v)=\left(\frac{\sum_{\bar{w} \in W} p_{\Pi}(\bar{w} \mid v)^{q}}{|W|}\right)^{1 / q}
$$

As a result, a sought set $P_{\Pi}\left(B_{0}\right)$ is obtained by the formula:

$$
P_{\Pi}\left(B_{0}\right)=\cup_{v \in B_{0}} P_{\Pi}(v) .
$$

For the quantitative assessments of the contribution of characteristics to the formation of a sought subset of high seismicity objects, the algorithm features additional computational units. In parallel with the computation of $p_{\Pi}(w \mid v)$, a binary matrix is formed $M_{\Pi}(w \mid v)$ :

$$
M_{\Pi}(w \mid v)_{i, j}=\left\{\begin{array}{c}
1, w_{i} \in P_{\pi_{j}}(v) \\
0, w_{i} \notin P_{\pi_{j}}(v)
\end{array} \quad, i=1, \ldots,|W|, j=1, \ldots,|\Pi| .\right.
$$

Every element of the matrix (9) determines whether or not the object $w \in W$ belongs to the set $P_{\pi_{j}}(v), \pi_{j} \in \Pi$ of the objects that are close to $v$. String summation of the matrix $M_{\Pi}(w \mid v)$ for all $w \in P_{\Pi}(v)$ forms the vector $W_{\Pi}(v)$ :

$$
W_{\Pi}(v)_{j}=\sum_{k} M_{\Pi}(w \mid v)_{k, j}, w_{k} \in P_{\Pi \Pi}(v), j=1, \ldots,|\Pi| .
$$

The elements of the vector (10) illustrate the contribution of characteristics $\pi_{j} \in \Pi$ to the formation of a subset $P_{\Pi}(v)$ of the objects that are close to $v \in B_{0}$. The quantitative assessments of the contribution of characteristics to the formation of $P_{\Pi}\left(B_{0}\right)$ are undertaken in two phases:

Element-by-element summation of all vectors $W_{\Pi}(v), v \in B_{0}$ and normalization on $\left|B_{0}\right|$ allows obtaining the average contribution of characteristics to the recognition of a sought high seismicity subset $P_{\Pi}\left(B_{0}\right)$. 
The sorting of $W_{\Pi}(v), v \in B_{0}$ and the selection for each of them of three characteristics with the greatest values, followed by the summation of the number of belongings of such characteristics to the formed threes, enable assessing the contribution of such characteristics through their classification as the "strongest." This class will be called Top 3 ranking. This explains the name of the algorithm Barrier-3.

The set of recognition objects is represented as a disjoint union of $W=B \amalg H$ high and low seismicity classes, $B=P_{\Pi}\left(B_{0}\right) \supseteq B_{0}$, and $H=W \backslash B$.

The Barrier-3 algorithm was employed as the EPA recognition block to recognize the areas prone to crustal earthquakes with $M \geq 6.0$ in the Caucasus and the Altai-SayanBaikal region. Here, 16 intersections of the axes of morphostructural lineaments with known epicenters of crustal earthquakes with $M \geq 6.0$, starting from 1900, in their vicinities (with a radius of $50 \mathrm{~km}$ in the Altai-Sayan-Baikal region and $25 \mathrm{~km}$ in the Caucasus) were used as the learning sets $B_{0}$ of high seismicity class in both regions.

The list of the geological-geophysical and geomorphological characteristics of considered vicinities of lineament intersections used for recognition by Barrier-3 algorithm is given in Table 1. Highlighted in bold type are 7 characteristics that were selected to be used for recognition in the Altai-Sayan-Baikal region based on the findings from the assessment of informativeness for the instance of one learning class; in italics, 11 characteristics selected for recognition in the Caucasus are given. It is noteworthy that 4 characteristics (Hmin, Top, R2, and dB) were selected for recognition using the Barrier-3 algorithm in both regions. Based on the threshold magnitude of the recognized earthquake-prone areas $(M \geq 6.0)$, the circles with a radius of $25 \mathrm{~km}$ were selected as vicinities within which the values of characteristics were computed. For reproducibility of the result and its greater reliability, the values of characteristics of objects were computed automatically using the smart GIS developed by the Geophysical Center of the Russian Academy of Sciences (http:/ / seismgis.gcras.ru/ access date: 30 July 2021) [19,20].

Table 1. The list of characteristics of the recognition objects (intersections of lineaments). Bold typecharacteristics used by the Barrier-3 algorithm for recognition in the Altai-Sayan-Baikal region; italics-the Caucasus; bold italics—both regions.

\begin{tabular}{|c|c|}
\hline Maximum height & $\operatorname{Hmax}$ \\
\hline Minimum height & Hmin \\
\hline The range of heights & $d H=H \max -H \min$ \\
\hline Distance between points where Hmax and Hmin are measured & 1 \\
\hline Height gradient & $\mathrm{dH} / 1$ \\
\hline The combination of relief types & Top \\
\hline The area of Quaternary sediments & $Q$ \\
\hline The highest rank of lineament & $H R$ \\
\hline The number of lineaments at the intersection & NL \\
\hline The distance to the nearest intersection & Rint \\
\hline Number of lineaments in the neighborhood of the intersection & $N L C$ \\
\hline The distance to the nearest lineament of rank I & R1 \\
\hline The distance to the nearest lineament of rank II & $R 2$ \\
\hline The maximum value of the Bouguer anomaly & Bmax \\
\hline The minimum value of the Bouguer anomaly & Bmin \\
\hline The range of the Bouguer anomaly values & $d B=B \max -B \min$ \\
\hline The maximum value of magnetic anomaly & MOmax \\
\hline The minimum value of magnetic anomaly & MOmin \\
\hline The range of the magnetic anomaly values & Modif = MOmax-MOmin \\
\hline
\end{tabular}




\subsection{Recognition of Strong Earthquake-Prone Areas Based on Identifying Dense Condensations of Point Objects}

In this part of the article, let us depart from the recognition objects described above (disjunctive nodes and intersections of the axes of morphostructural lineaments) and their geological-geophysical and geomorphologic characteristics. The task considered here will be closer to reality. Namely, in addition to the reliable classification of a finite set of point objects, a formalized and reproducible transition from a recognized high seismicity set $B$ to a real two-dimensional region in the plane with the cardinality of the continuum will be required. Strong earthquakes can occur within and cannot occur outside of this sought region. In other words, the innovation we make to the statement of the problem will be building an image of the set of recognition objects $W$ in the studied region $S$ as in the subset of the Euclidean plane:

$$
F_{\gamma}: W \rightarrow F_{\gamma}(W) \subset S \subset R^{2},
$$

where $\gamma$ is a set of free mapping parameters $F_{\gamma}$ [21].

A sought mapping $F_{\gamma}$ must meet the following necessary conditions:

(a) flat set $F_{\gamma}(B) \subset S$ is obtained for $B \subset W$, given the fixed values of free parameters $\gamma$,

(b) flat set $F_{\gamma}(B)$ contains high seismicity objects $w \in B$ as points in the plane, i.e., $\forall w \in B \Rightarrow w \in F_{\gamma}(B)$, and

(c) the epicenters of known strong earthquakes $\left(M \geq M_{0}\right)$ are located inside or at the borders of zones $F_{\gamma}(B)$. That said, given possible errors in the identification of historic epicenters, they can be located near the borders $F_{\gamma}(B)$.

It is natural to view such two-dimensional sets $F_{\gamma}(B)$ of the cardinality of the continuum as actual flat zones within which strong earthquakes can occur. The selection of values $\gamma$ of any given variant among those that meet the conditions (a), (b), and (c) is based on the system approach using control experiments.

The algorithmic system called Formalized Clustering and Zoning (FCAZ) developed by the authors [21,22] is used as sought mapping $F_{\gamma}$. It represents systems analysis method concerning Discrete Mathematical Analysis (DMA) [23-30].

The FCAZ method enables an effective recognition of strong earthquake-prone areas based on the cluster analysis [31] of a catalog of seismic events. It represents a consistent application of Discrete Perfect Sets (DPS) algorithms [21,32-34] and E ${ }^{2}$ XT [22] (Figure 1). Unlike the EPA procedure, the FCAZ systems analysis method uses neither morphostructural zoning nor dichotomy learning algorithms. It relies on the topological filtering of a finite set of epicenters of fairly weak earthquakes, which act as recognition objects.

The fundamental difference of the FCAZ systems method from the EPA procedure is that FCAZ has a formalized block ( $E^{2} X T$ algorithm) of passing from the classification of a finite set of point objects to sought flat high seismicity zones. The $E^{2} X T$ block constructs an unambiguous mapping of a set of objects identified by the DPS algorithm in the flat zones of non-zero measure. Strong earthquakes can occur within and at the boundary of such zones. Such mapping allows for the first time to switch in the problem of earthquake-prone areas recognition from the simple pattern recognition to full-fledged systems analysis. Specifically, this makes it possible to unambiguously isolate, using sharp bound, a subsystem of recognized high seismicity zones from their non-empty complement.

The core of FCAZ is the DPS topological filtering algorithm (Figure 1) [21] isolating clusters as own subsets in a set $W$. This is what makes DPS different from classical clustering algorithms. It is aimed at isolating in a finite set of Euclidean space of flat regions with a given density level $\alpha$.

It should be emphasized that DPS is effective for the considered problem exactly because it distinguishes between compact, connected groups of objects and their fuzzy, unstructured complement. In other words, DPS cuts out isolated objects, "attracting" the rest into dense clusters. That said, unlike classical clustering algorithms, in DPS by no means all objects end up in clusters. This is what makes DPS new and innovative as a systems analysis algorithm. 


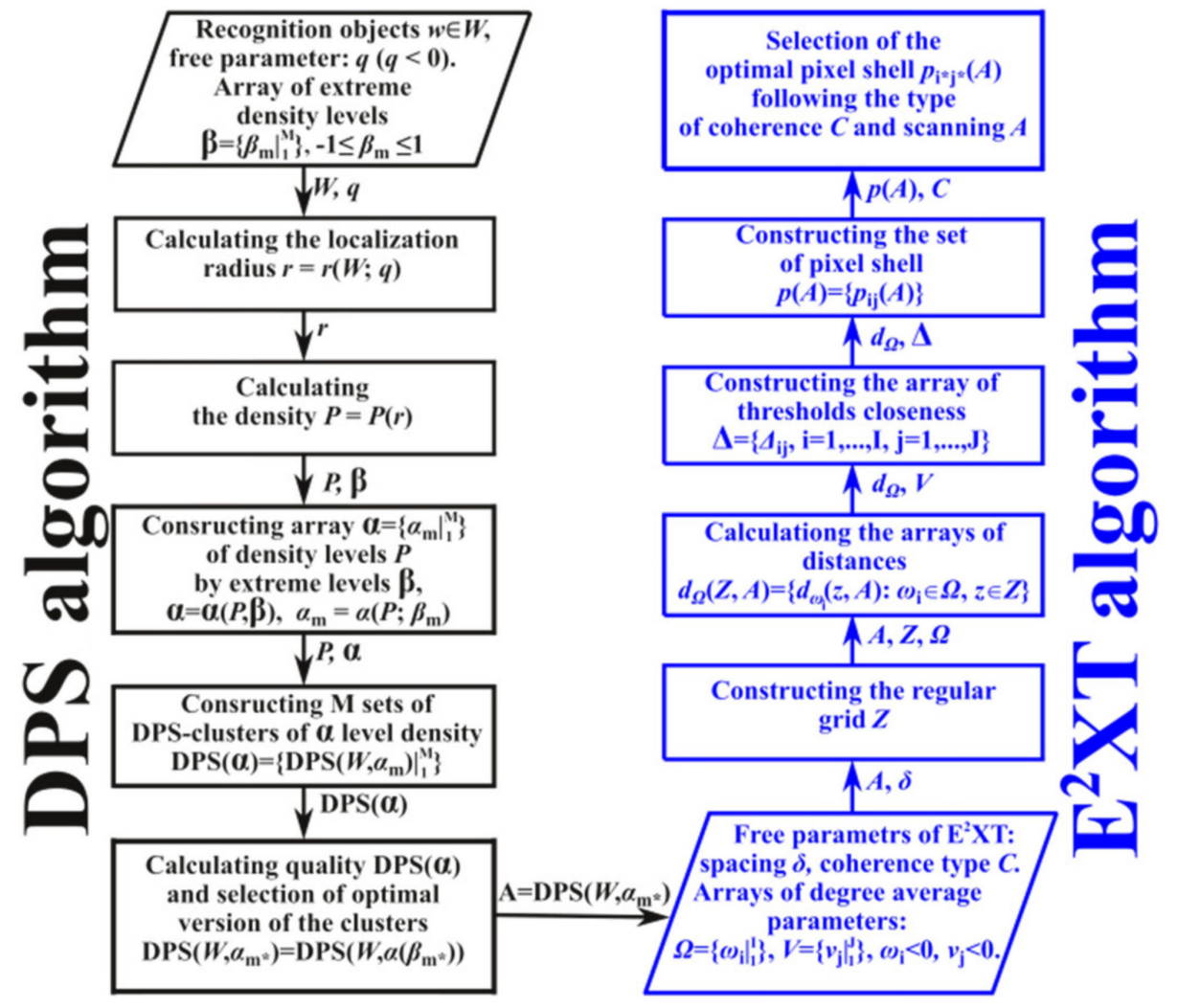

Figure 1. The flow chart of system-analytical FCAZ method. Black blocks-DPS algorithm steps; blue blocks- $\mathrm{E}^{2} \mathrm{XT}$ algorithm.

The DPS algorithm has two free parameters: $q<0$ for the calculation of localization radius $r_{q}(W)$, which is determined as the power mean of all nontrivial pairwise distances in a set of recognition objects $W$, and $\beta \in[-1,1]$ is the maximality level of the necessary density of $\alpha=\alpha(\beta, q)$ DPS clusters. The output value is a set $(\alpha(\beta, q)) \alpha$, which is dense in each of its elements.

The result of applying the DPS algorithm is as follows:

$$
\operatorname{DPS}(q, \beta): W \rightarrow\left\{B_{1}, \ldots, B_{n}\right\},
$$

where parameters $q$ and $\beta$ determine a particular type of DPS clusters; $B_{1}, \ldots, B_{n}$, own connected subsets in a set of recognition objects. In other words, $B=\coprod_{i=1}^{n} B_{i}$, where $B_{i}$, $i=1, \ldots, n$ are recognized DPS clusters, $B, B_{i} \subset W$, and $W \backslash B$ represents a significant part of the set $W$. It is noteworthy that if the latter is false, then the recognition result is trivial.

During the next phase, DPS clusters $B_{1}, \ldots, B_{n}$ are transformed by the $\mathrm{E}^{2} \mathrm{XT}$ algorithm into flat zones of the cardinality of the continuum (i.e., mapping of $F_{\gamma}$ is performed). During this phase, mapping is constructed:

$$
\mathrm{E}^{2} \mathrm{XT}(\delta, C, \omega, v): B_{i} \rightarrow F\left(B_{i}\right),
$$

where $\delta$ is the step of the geographical grid, $\omega<0, v<0$ are free parameters, $C$ is connection type, $B_{i}$ are determined by the formula (12), $F\left(B_{i}\right), i=1, \ldots, n$ are sought flat zones of non-zero measure. If mapping (13) meets the above conditions (a), (b), and (c), then $F\left(B_{i}\right)$ there are sought areas prone to strong earthquakes.

Accordingly, the FCAZ system is a composition of two algorithms:

$$
\operatorname{FCAZ}(\gamma)=\mathrm{E}^{2} \mathrm{XT}(\delta, C, \omega, v) \circ \operatorname{DPS}(q, \beta)
$$


and $\gamma$ is a set of free parameters of FCAZ:

$$
\gamma=\{\delta, C, \omega, v\} \cup\{q, \beta\}=\{\delta, C, \omega, v, q, \beta\} .
$$

The existence of mappings (13-15) allows considering FCAZ as a systems analysis method. $\operatorname{FCAZ}(\gamma)$, indeed, processes input data from beginning to end in a unified system. That said, the solution presented takes shape of sought two-dimensional zones and not their palliatives, representing finite sets of points in the plane [21].

The constructions of DPS and $E^{2} \mathrm{XT}$ algorithms feature artificial intelligence blocks that automatically select optimal values $\beta$ in DPS and $\omega, v$ in $\mathrm{E}^{2} \mathrm{XT}$. This makes the result of FCAZ recognition objective and reproducible. An optimal value $\beta$ enables recognizing DPS clusters for which the difference between the totality of densities (in the inherent sense of the algorithm) of objects inside the clusters and the totality of densities of objects outside of the clusters will be the greatest possible. The selected $\omega$ and $v$ make it possible to find an optimal combination of connection and scannability of DPS clusters. A detailed description of mathematical constructions of the DPS and $\mathrm{E}^{2} \mathrm{XT}$ algorithms is provided in the papers [21,22].

FCAZ delivers a system approach to studying strong earthquake-prone areas. Its characteristic property lies in the fact that the recognition of sought zones in the regions of the globe that differ in structure relies on universal facts and methods, which enable a uniform approach toward solving the entire class of such problems. The statement of the problem and the process of its solving represent a unified system that is sufficiently invariable relative to geological structure, the selection of threshold magnitudes of sought strong earthquakes, objects, etc. That said, the FCAZ applicability condition is the state of seismological and geological-geophysical exploration of regions, which manifests itself in the high quality of earthquake catalog.

The next parts of the paper will demonstrate how FCAZ allows performing reliable recognition of the strongest $(M \geq 7.75)$, strong $(M \geq 6.0)$, and significant earthquakeprone areas across different mountain countries of the world. The reliability of obtained results was assessed with the help of control experiments and through comparison with high seismicity zones recognized by EPA approach. The division of earthquakes into the strongest, strong, and significant ones was made by the authors solely to simplify the description of the results obtained.

It should be noted that previously the recognition of high seismicity zones was performed just for one fixed magnitude threshold $M_{0}$. In the present paper, a method for the successive recognition of the areas prone to earthquakes for different threshold magnitudes in the same region is proposed. It is based on the repeated application of FCAZ method to a set of recognition objects, which is successively narrowed down by way of DPS clustering. The new method was called Successive Formalized Clustering and Zoning and is abbreviated as SFCAZ [35]. Accordingly, the classical EPA problem formulated at the beginning of the article is for the first time expanded to a more systemic complicated problem of the successive recognition of the areas prone to earthquakes in the same region for several threshold magnitudes. The mathematical construction of the SFCAZ method is described in detail in the paper [35].

\section{Results}

\subsection{Variable EPA Method}

Figure 2 shows the MSZ map of Altai-Sayan-Baikal region. The result of earthquakeprone areas recognition with $M \geq 6.0$ by Barrier-3 algorithm is shown in Figure 2 using ellipses with blue boundaries. Upon the completion of recognition, 32 out of 97 objects are identified as high seismicity class $B$. The totality of vicinities of these objects (circles used to compute the values of characteristics) [5] determines the areas prone to earthquakes with $M \geq 6.0$. 


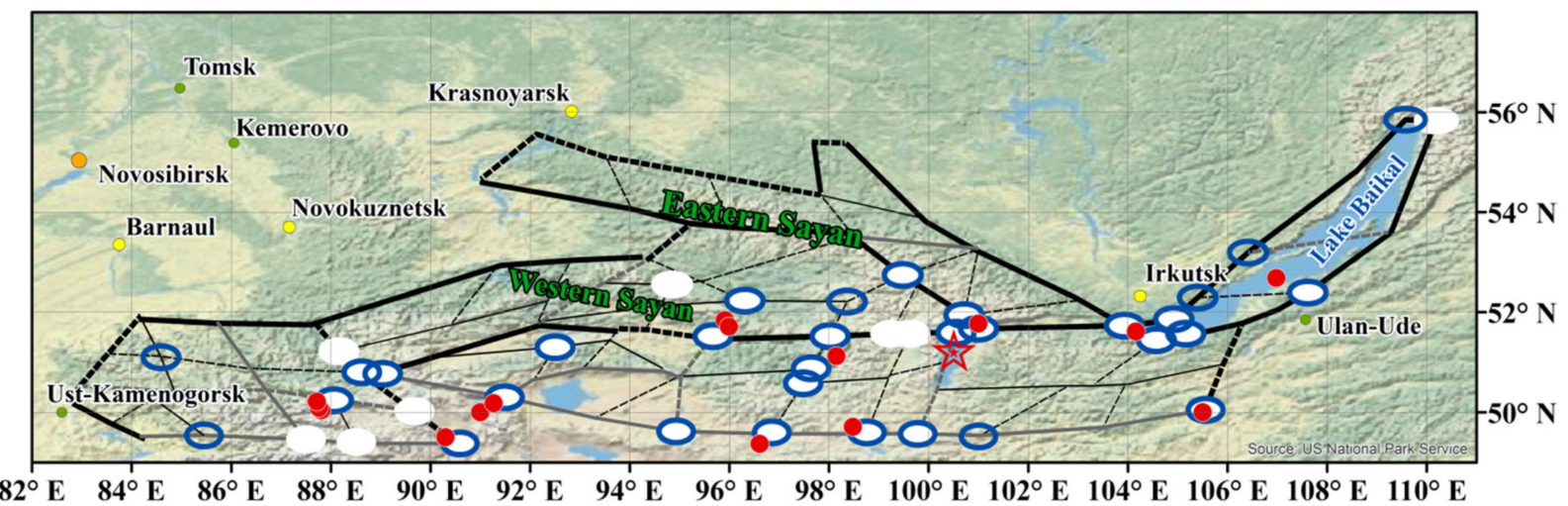

Figure 2. The morphostructural zoning map of the Altai-Sayan-Baikal region. Thick black lines—rank I lineaments; medium gray lines—rank II; thin black lines—rank III; solid lines—longitudinal lineaments; dotted line—transverse ones [36,37], areas prone to earthquakes with $M \geq 6.0$ (ellipses with blue boundaries—Barrier-3 [16], white ellipses-Cora-3 [37], white ellipses with blue boundaries — both the algorithms). Red circles designate the epicenters of crustal earthquakes with $M \geq$ 6.0 (1900-2012) used to form the learning set $B_{0}$, red star refers to the epicenter of crustal earthquake (11 January 2021 with $M=6.7$ ) that occurred after the completion of recognition.

Figure 3a shows a bar diagram characterizing the medium contribution of characteristics in recognition using the Barrier-3 algorithm of a sought high seismicity set of objects. Figure $3 \mathrm{~b}$ shows the contribution of characteristics expressed through attribution to the Top 3 rankings. The $y$ axis in Figure 3 a shows the average number of "attributions" of characteristics in the recognition of a set $P_{\Pi}\left(B_{0}\right)$ (see above), in Figure $3 b$, the number of attributions to the three "strongest" characteristics (Top 3 ranking).

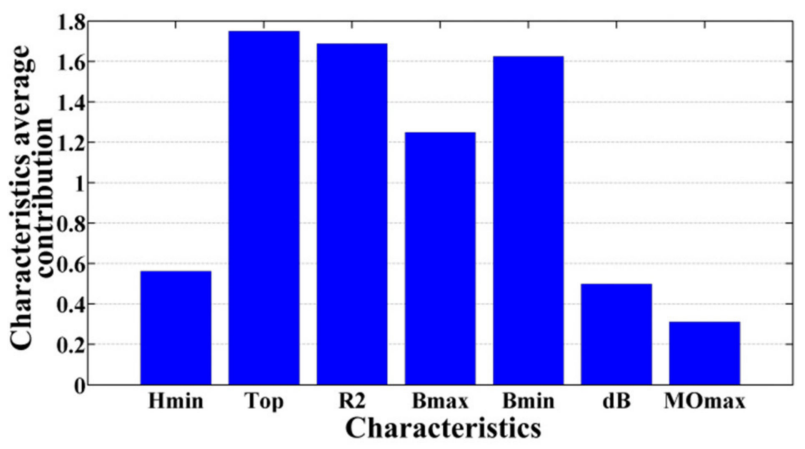

(a)

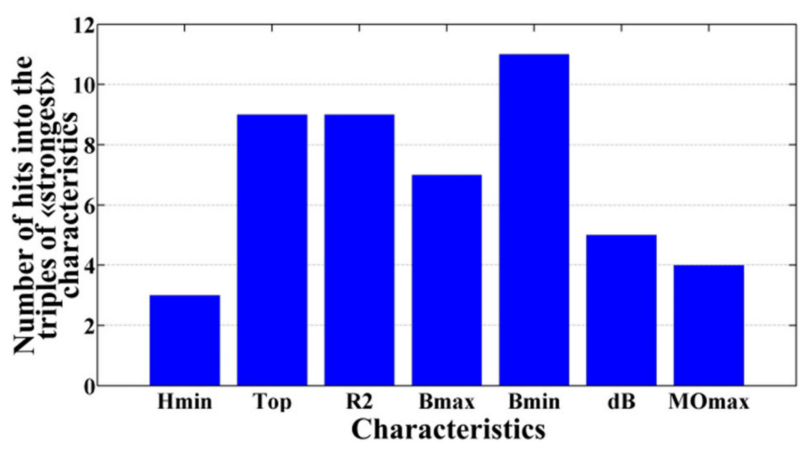

(b)

Figure 3. The contribution of characteristics to recognition using the Barrier-3 algorithm of a high seismicity set of objects in the Altai-Sayan-Baikal region: (a) average contribution of characteristics; (b) the contribution of characteristics expressed through their attribution to the "strongest" threes.

It can be seen from Figure 3 that in the recognition of strong earthquake-prone areas in the Altai-Sayan-Baikal region using the Barrier-3 algorithm, the most significant characteristics include gravity anomalies (Bmax and Bmin), a combination of relief types (Top) and the distance to the nearest lineament of rank II (R2). The intersections of lineaments classified as high seismicity ones against the background of the entire set of objects in their vicinities are characterized by low values of gravity anomalies (mostly Bmax $\leq-160 \mathrm{mGal}$ and Bmin $\leq-220 \mathrm{mGal}$ ) and contrasting combinations of relief types-mountains/foothill and mountains/mountains. These are characterized by high values of magnetic anomaly (MOmax), the concentration of $\mathrm{dB}$ around $60 \mathrm{mGal}$ and $120 \mathrm{mGal}$, and the concentration of Hmin less than $-1000 \mathrm{~m}$ and more than $1000 \mathrm{~m}$.

It can be seen from Figure 3 that lithospheric magnetic field anomalies contribute to the result of recognition in the Altai-Sayan-Baikal region. It can thus be concluded that the vicinities of high seismicity intersections of lineaments are characterized by a high degree 
of tectonic breaks, the existing deep density heterogeneity, as well as specific structure and composition of the Earth's crust. It would be natural to interpret these signs as the criteria of high seismicity in the studied region.

A comparative analysis of results, obtained independently using the Barrier-3 algorithm and the Cora-3 dichotomy algorithm, which is most common in the EPA [38,39], shows that they are well aligned with each other (Figure 2). The Barrier-3 algorithm recognized as high seismicity ones 32 intersections of morphostructural lineaments and Cora-3 33 intersections [36,37]. That said, 25 objects were attributed by both algorithms to class $B$.

The Barrier- 3 algorithm classified as hazardous 6 out of 51 objects of the learning set of a low seismicity class of dichotomy; Cora-3 3 out of 51; both algorithms, 2 intersections. Consequently, 44 learning objects of class $H$ were recognized by both algorithms as nonhazardous for magnitude $M \geq 6.0$. It means that the key differences in the classification belongs to a set of objects initially not attributed to learning sets ( 20 objects are classified identically by the algorithms and 10 are classified differently). It should be noted that the epicenters of earthquakes with $M \geq 6.0$, used to form the learning set $B_{0}$ (red circles in Figure 1) are located strictly within the vicinities of objects classified by both algorithms as high seismicity ones [16,37].

It is noteworthy that the Barrier-3 algorithm is structured in such a way that learning objects in the final classification always belong to class $B$. In turn, in recognition using dichotomy algorithms (particularly Cora-3 algorithm), learning objects are broadly speaking, not obliged to retain their attribution to the relevant class [4,7].

The red star in Figure 2 shows the epicenter of the crustal earthquake, which occurred on 11 January 2021, with $M=6.7$. This earthquake occurred after the completion of the independent recognitions described herein using the Barrier-3 and Cora-3 algorithms, thus representing the material for a pure examination for them. It can be seen from Figure 2 that the epicenter is located outside of the vicinities (with a radius of $25 \mathrm{~km}$ ) of the intersections of lineaments recognized as high seismicity ones by both algorithms. At the same time, it is located $42 \mathrm{~km}$ away from the nearest recognition object attributed to class $B$ by both algorithms. It was believed in the formation of learning material that the epicenter is confined to the intersection if it is located at a distance of no more than $50 \mathrm{~km}$. Accordingly, the epicenter of the earthquake that occurred on 11 January 2021, is confined to the intersection of lineaments attributed to class $B$ by both algorithms, yet is located outside of the $25 \mathrm{~km}$ of vicinities used to compute the values of its characteristics.

The recognition results of the areas prone to earthquakes with $M \geq 6.0$ in the AltaiSayan-Baikal region, obtained using the Barrier-3 (one learning class) [16] and Cora-3 algorithms (two learning classes) [36,37], are well aligned with each other. On the one hand, this evidences the reliability of both results since recognition was performed independently. On the other hand, in the interpretation of differences $(15.5 \%$ of the total number of objects) in the outcomes, preference should be given to the classification using the Barrier- 3 algorithm since it was performed with learning containing no protentional errors.

The recognition result of the areas prone to strong earthquakes in the Caucasus, obtained using the Barrier-3 algorithm as the EPA recognition block, is shown in Figure 4 as ellipses with blue boundaries. Barrier- 3 attributed 108 out of 237 intersections of lineaments to high seismicity class $B$.

Figure 5 shows the bar diagrams demonstrating the contribution of object characteristics to the recognition, by Barrier-3 algorithm, of the intersections of lineaments, in whose vicinities strong earthquakes can occur in the Caucasus. As it can be seen, the greatest contribution is made by the characteristics that are responsible for relief heights (Hmax and Hmin), the area of quaternary rocks (Q), the highest rank of lineament (HR), the number of lineaments in the vicinities (NLC), and the distances to the nearest lineaments of ranks I (R1) and II (R2). 


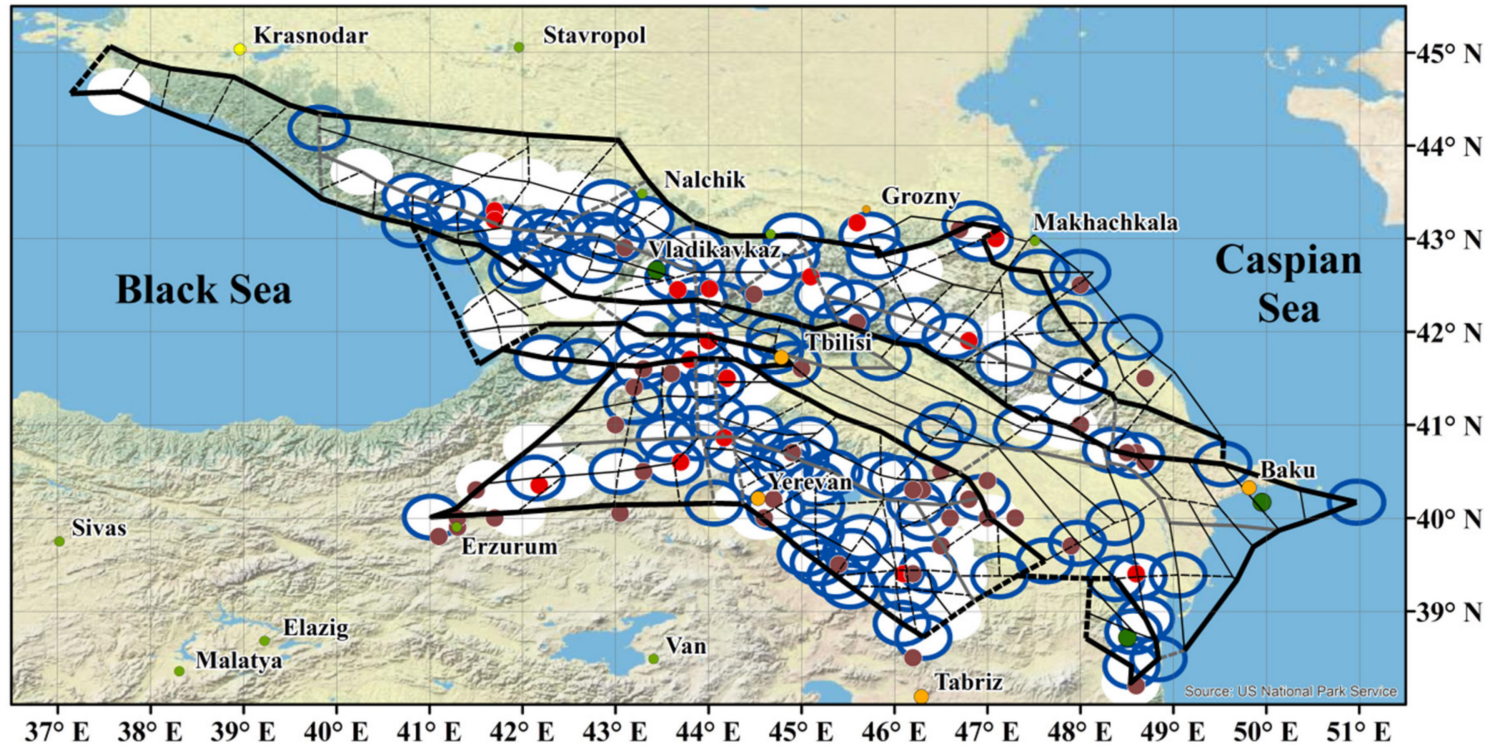

Figure 4. The morphostructural zoning map of the Caucasus (legends as in Figure 2) [40], areas prone to earthquakes with $M \geq 6.0$ (ellipses with blue boundaries-Barrier-3 [17], white ellipses-Cora-3 [41], white ellipses with blue boundariesboth algorithms) and the epicenters of earthquakes with $M \geq 6.0$ (brown circles—before 1900, red circles-in the period from 1900 to 1992 (used to form the learning set $B_{0}$ ), dark green circles—since 1993 (material for a pure exam)) [42].

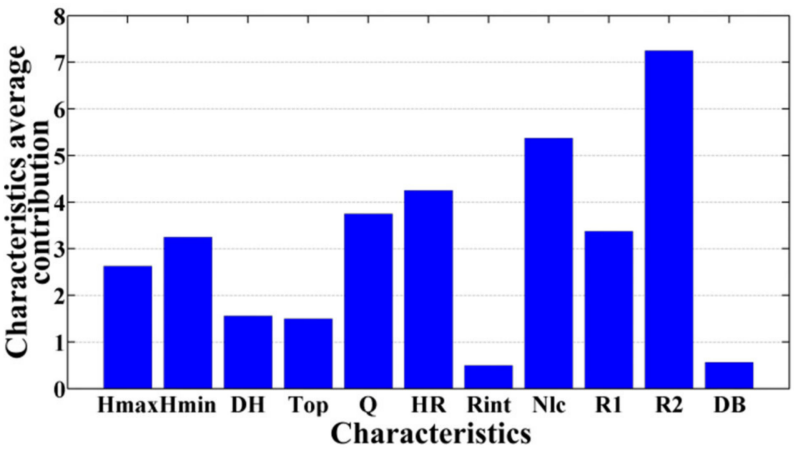

(a)

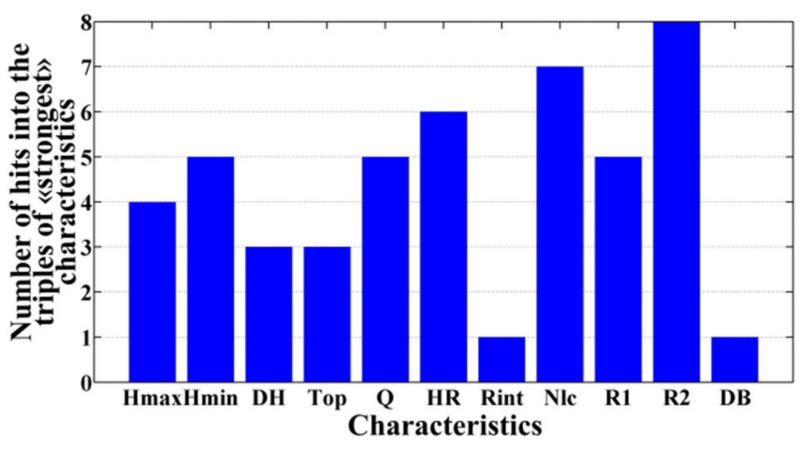

(b)

Figure 5. The contribution of characteristics to the recognition, using the "Barrier-3" algorithm, of a high seismicity set of objects in the Caucasus: (a) average contribution of characteristics; (b) the contribution of characteristics expressed through their attribution to the "strongest" threes.

In the Caucasus, the intersections of lineaments recognized as hazardous ones for $M \geq 6.0$ against the background of the entire set of recognition objects in their vicinities are characterized by high values of the maximum and minimum heights (Hmax $\geq 2500 \mathrm{~m}$ and $\mathrm{Hmin} \geq 600 \mathrm{~m})$ and a small area of quaternary rocks $(\mathrm{Q} \leq 30 \%)$. They are made up of three or more lineaments of ranks II or III (NLC $\geq 3, \mathrm{HR}=2$ or $\mathrm{HR}=3, \mathrm{R} 2 \leq 30 \mathrm{~km}$ ) and located at a relatively short distance away from the lineaments of rank $\mathrm{I}(0<\mathrm{R} 1 \leq 50 \mathrm{~km})$.

The joint analysis of Figures 3 and 5 shows that in both regions for the Barrier-3 algorithm, a significant contribution to the formation of a high seismicity set of objects is made by the distance to the nearest lineament of rank II. Namely, the characteristic R2 is important for the Barrier-3 algorithm and invariable relative to the selection out of two regions considered.

Figure 4 illustrates a comparison of the classification of lineament intersections in the Caucasus, obtained with the help of Barrier-3 and Cora- 3 algorithms. The first one recognized as high seismicity ones 108 intersections of lineaments [17]; the second one, 107 [41], both algorithms simultaneously recognized 73. The Barrier-3 algorithm classified as hazardous 24 out of 71 objects of the learning set of low seismicity class from Cora-3; Cora- 
3, 22; both algorithms simultaneously, 16. In total, 41 learning objects of a low seismicity class were recognized by both algorithms as non-hazardous. Out of the intersections set not initially classified as the learning sets of Cora-3, the algorithms classified identically 95 objects and classified differently 55 objects $[17,41]$.

It can be seen from Figure 4 that the objects located on the longitudinal lineaments of rank II and classified by both algorithms as high seismicity ones make up extensive zones along the axis of the Main Ridge in the Central and Southeastern Segments of the Greater Caucasus. A good coincidence of recognition results can be seen in the eastern sector of the Lesser Caucasus and the Armenian Volcanic Plateau [43]. A totality of the objects located on the transverse lineaments of rank II and attributed by the Barrier-3 and Cora-3 algorithms to class $B$ make up an extensive submeridional zone within the Trans-Caucasian Transverse Elevation, combining the areas prone to strong earthquakes in the Greater and Lesser Caucasus. A fairly good alignment of high seismicity areas can also be seen near the Talysh mountains. It is noteworthy that most earthquakes known in the Caucasus with $M \geq 6.0$ occurred in the vicinities of the objects making up the zones described above.

The analysis of Figure 4 showed that all 17 epicenters of earthquakes with $M \geq 6.0$ (red circles), which formed the learning set of high seismicity class of both algorithms, are located inside the $B$ zones recognized by both algorithms. Out of 42 epicenters of strong earthquakes, which occurred before 1900 (brown circles), 7 and 8 epicenters, respectively, are located outside of the zones recognized by the Barrier-3 and Cora-3 algorithms. Half of them are located within a short distance from the potentially high seismicity areas recognized by the algorithms.

Dark green circles in Figure 4 refer to the epicenters of strong earthquakes, which have occurred in the Caucasus since 1993. Information about them has not been used, in any manner whatsoever, in the formation of learning sets; thus these earthquakes represent material for a pure examination. Two of the three epicenters are located strictly within the high seismicity zones recognized by both algorithms. The latter represents a significant argument in favor of the reliability of the result demonstrated by Figure 4.

The replacement of a dichotomy algorithm with the original Barrier-3 algorithm, undertaken in this paper, is an attempt to open a new page in the development of the EPA approach. As shown above, the Barrier-3 algorithm proved itself to be good in the recognition of strong earthquake-prone areas with one learning class in the Caucasus and the Altai-Sayan-Baikal region. This fact strengthens the assumptions that the approach toward the recognition of potentially high seismicity zones based on the only high seismicity learning class through its expansion is adequate to the classical setting of the EPA problem.

The positive variants for recognition obtained using the Barrier-3 and Cora- 3 algorithms make them control experiments for each other. Due to the relative proximity of results, these control experiments should be recognized as successful. This enhances the assessment of the reliability of the above results.

The studied regions serve as a basis for the proposed joint interpretation of the strong earthquake-prone areas recognized for one and two learning classes. The interpretation relies on the composition of unclear set construction [44] and the results obtained independently using the Barrier-3 algorithm and the Cora-3 dichotomy [45].

Let $W$ still represent a set of intersections of lineaments, and a fuzzy set of high seismicity objects is defined as a set of pairs:

$$
B=\left\{w, \mu_{B}(w) \mid w \in W\right\}
$$

That said, membership function $\mu_{B}(w)$ is:

$$
\mu_{B}(w)=\mu_{\mathrm{B}_{1}, \mathrm{~B}_{2}}(w)=\left\{\begin{array}{c}
1, w \in B_{1} \cap B_{2} \\
0.5, w \in B_{1} \Delta B_{2} \\
0, w \notin B_{1} \cup B_{2}
\end{array}=\left(B_{1} \cup B_{2}\right) \backslash\left(B_{1} \cap B_{2}\right),\right.
$$


where $B_{1}$ and $B_{2}$ are the sets of objects recognized as high seismicity ones by the Barrier-3 and Cora-3 algorithms, respectively. Then high seismicity objects in the integral result are the intersections for which $\mu_{B}(w)>0$.

Figure 6 provides the example of an interpretation of results for strong earthquakeprone areas recognition with $M \geq 6.0$ in the Caucasus and the Altai-Sayan-Baikal region using a fuzzy set construction (16-17). In the Altai-Sayan-Baikal region in line with the obtained independent results of recognition (Figure 2), all considered epicenters of strong earthquakes are located in the vicinities of objects attributed to class $B$ by both algorithms. Whether or not the epicenter of the 2021 earthquake should be treated as a "missed target" error, the number of missed recognition targets in cases where a fuzzy function is used (Figure 6a) is the same for each algorithm (Figure 2). In this case, recognition using the Formulas (16) and (17) only increases the number of sought high seismicity objects, where strong earthquakes have not been recorded until the present.

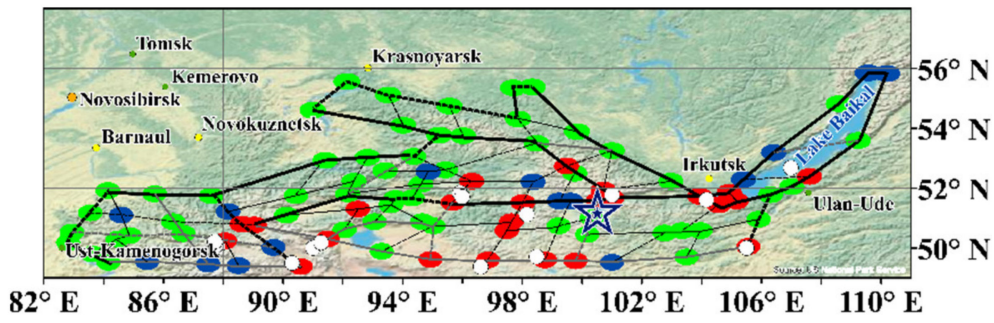

(a)

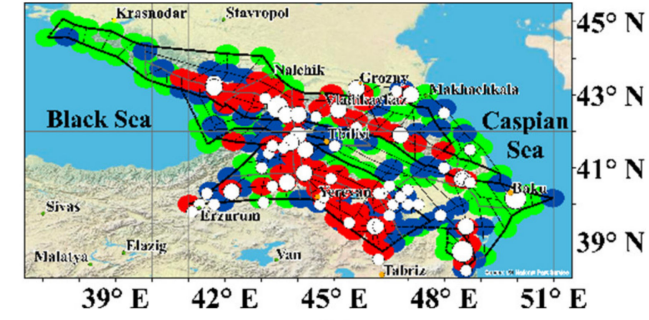

(b)

Figure 6. Presentation of a joint result of earthquake-prone areas recognition with $M \geq 6.0$ by the Barrier-3 and Cora-3 algorithms as a fuzzy set of vicinities of the intersections of lineaments: (a) the Altai-Sayan-Baikal region (white circlesepicenters of earthquakes with $M \geq 6.0$ (1900-2012); blue star-epicenter of the earthquake, which occurred on 11 January 2021); (b) the Caucasus (white circles—epicenters of earthquakes with $M \geq 6.0$; minor ones—before 1900; medium ones1900-1992; major ones-after 1992). Highlighted in red are the vicinities of intersections of lineaments with membership function to the high seismicity set $\mu=1$; in blue, $\mu=0.5$; in green, $\mu=0$. The function $\mu$ is determined by the formula (17).

The situation in the Caucasus is different. The fuzzy function approach a priori improves the quality of the result here. In Figure 4, out of 62 epicenters of the considered earthquakes with $M \geq 6.0,8$, and 9 epicenters, respectively, lie outside of the high seismicity areas recognized by the Barrier-3 and Cora- 3 algorithms. That said, as few as 4 epicenters are located outside of the zones identified as high seismicity ones (red and blue ellipses in Figure $6 \mathrm{~b}$ ) based on the Formulas (16) and (17).

The integral result (Figure 6) identifies $41.2 \%$ of objects in the Altai-Sayan-Baikal region and $59.9 \%$ in the Caucasus as high seismicity ones. That said, for the studied EPA problem, the result is typically treated as nontrivial if not more than $60 \%$ of objects are classified as high seismicity ones [4]. The recognition obtained based on the Formulas (16) and (17) meets this condition for both regions. At the same time, this allows obtaining a new nontrivial result for both regions and halving the number of missed targets in the Caucasus.

The improvement of recognition result when construction (16-17) is used derives from the fact that the employment of fuzzy mathematics enables integrating the criteria of two independent recognitions performed by the Barrier-3 and Cora- 3 algorithms. This allows, to some extent, compensating incomplete and sometimes defective input data [45].

\subsection{FCAZ Recognition of the Strongest Earthquake-Prone Areas}

Three regions of the Pacific Seismic Belt are considered. Within their limits by the FCAZ method the areas prone to the strongest earthquakes with $M \geq 7.75$ are recognized. The epicenters of earthquakes with the focal depth of up to $70 \mathrm{~km}$ from the ANSS catalog (1963-2013, the mountain belt of the South American Andes), the earthquakes catalog of Kamchatka and the Commander Islands (1962-2015, the coast of the Kamchatka Peninsula), and the catalog of the Kuril-Okhotsk region (1962-2009, the coast of the Kuril Islands) are 
used as recognition objects. To select the magnitude threshold $M_{R}$, starting from which the epicenters were used as recognition objects, completeness magnitude $M_{\mathcal{C}}$ was assessed in the catalogs [46-48]. Taking into account $M_{\mathrm{c}}$ assessment, it was decided to use as FCAZ recognition objects in the Andes the earthquake epicenters with $M \geq M_{R}=4.5(16,556$ epicenters) [21]; in Kamchatka, $M \geq M_{R}=3.5$ (44,113 epicenters) [49-51]; in the Kuril Islands, $M \geq M_{\mathrm{R}}=4.2$ (11,725 epicenters). In Figure $7 \mathrm{a}$, the totality of blue and green colors shows recognition objects in the mountain belt of the South American Andes.

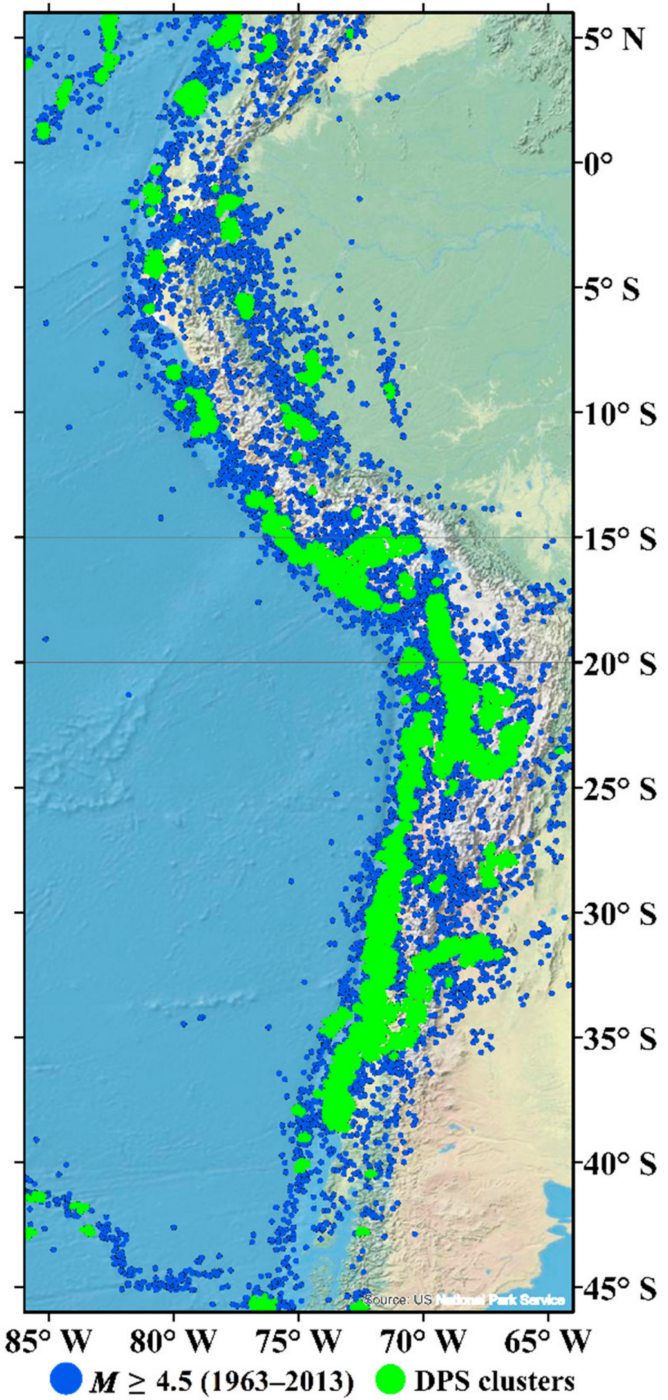

(a)

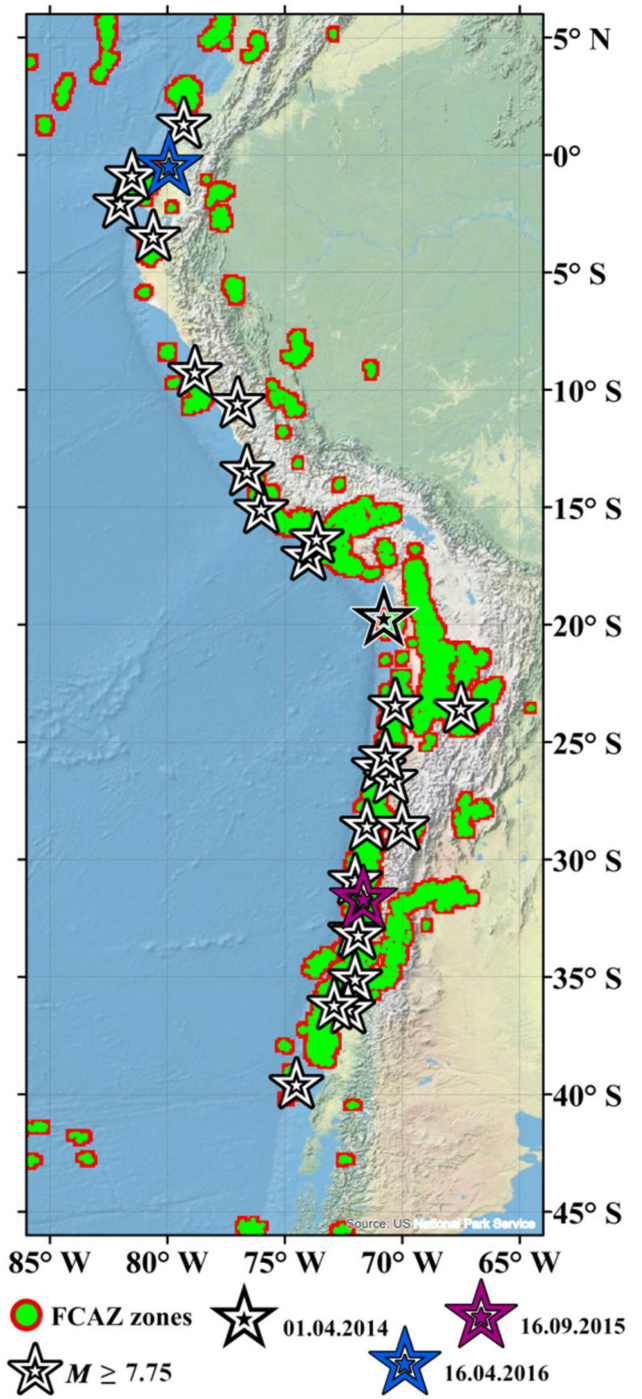

(b)

Figure 7. Mountain belt of the Andes: (a) FCAZ recognition objects-the epicenters of earthquakes with $M \geq 4.5$ and recognized DPS clusters; (b) FCAZ zones prone to earthquakes with $M \geq 7.75$ and the epicenters of earthquakes with $M \geq 7.75$.

The lists of the strongest crustal earthquakes, beginning in 1900, have been formed based on the above-listed instrumental catalogs, EPA recognition works, and the catalog of strong earthquakes in the USSR from ancient times to 1975 [52]. As a result, the catalog of the strongest earthquakes of the mountain belt of the Andes contains 24 events for the period of 1900-2013; the catalog of Kamchatka, 8 (1900-2015); and that of the Kuril Islands, 11 (1900-2009). The epicenters of earthquakes with $M \geq 7.75$ are shown in Figures $7 \mathrm{~b}$ and 8 . 


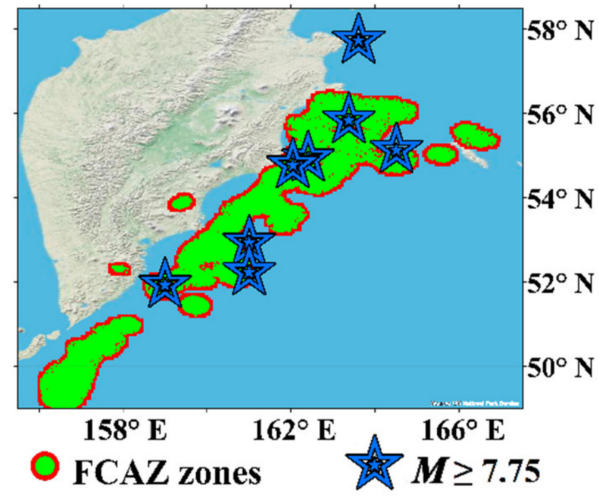

(a)

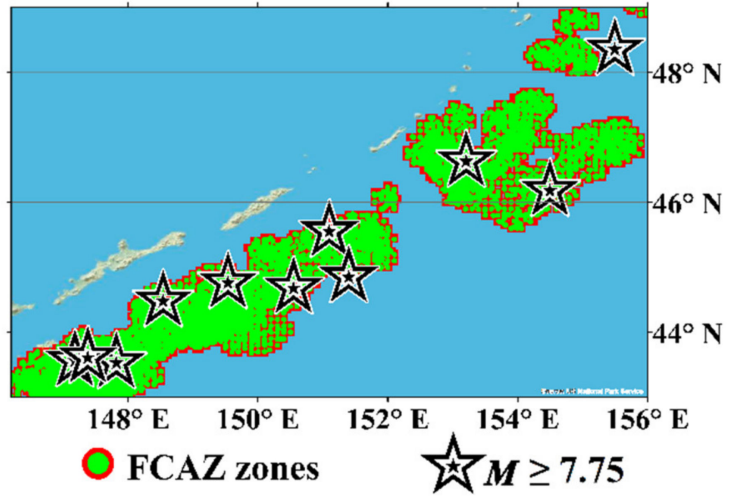

(b)

Figure 8. FCAZ zones prone to earthquakes with $M \geq 7.75$ and the epicenters of earthquakes with $M \geq 7.75$ : Pacific Coast (a) of the Kamchatka Peninsula; (b) of the Kuril Islands.

The DPS clustering of the epicenters of earthquakes, which represent FCAZ recognition objects, was performed as follows. Initially, the DPS algorithm was employed with density level $\alpha_{1}\left(\beta_{1}\right)$. The obtained dense set of objects $W_{1}\left(\alpha_{1}\left(\beta_{1}\right)\right)$ was excluded from further consideration and the algorithm was applied for the second time to the remaining subset with density level $\alpha_{2}\left(\beta_{2}\right)$. This allowed obtaining new DPS clusters $W_{2}\left(\alpha_{2}\left(\beta_{2}\right)\right)$, where $W_{2}=W \backslash W_{1}\left(\alpha_{1}\left(\beta_{1}\right)\right)$. Subsequent iterations were performed similarly. All connected components forming part of $W_{1}\left(\alpha_{1}\left(\beta_{1}\right)\right) \cup W_{2}\left(\alpha_{2}\left(\beta_{2}\right)\right) \cup \ldots \cup W_{k}\left(\alpha_{k}\left(\beta_{k}\right)\right)$ were declared as sought DPS clusters.

Four iterations of DPS clustering were performed in the mountain belt of the South American Andes; two iterations, in Kamchatka; and three, in the Kuril Islands. The optimal values of the $\beta$ parameter - the maximality level of density of DPS clusters-were computed automatically using the artificial intelligence block. It should be noted that $67 \%$ of recognition objects in the mountain belt of the Andes were included in the recognized DPS clusters; 73.3\%, in Kamchatka; 77.5\%, in the Kuril Islands. DPS clusters are highlighted in green in Figures 7 and 8.

In each of the three regions, the $\mathrm{E}^{2} \mathrm{XT}$ algorithm was applied to DPS clusters. The optimal values of its input parameters $\omega$ and $v$ were computed using the artificial intelligence block. That said, a regular geographical graticule and connection type $C_{8}$ was used. In Figures $7 \mathrm{~b}$ and 8 , the totality of green and red colors shows mapped FCAZ zones.

Figures $7 \mathrm{~b}$ and 8 show that FCAZ zones are well aligned with the location of the epicenters of the known strongest earthquakes. Out of 24 earthquakes with $M \geq 7.75$ in the mountain belt of the Andes, only one epicenter (4.2\%) is located outside of FCAZ zones (Figure $7 \mathrm{~b}$ ) and creates a missed target error. This is an epicenter of the earthquake which occurred on 24 May 1940, more than 20 years before the commencement of systemic instrumental seismological observations in the region. Accordingly, the location of the epicenter can be distorted and this only error can be irrelevant.

Out of the eight strongest earthquakes considered in the Pacific Coast of the Kamchatka Peninsula, the epicenter of just one (12.5\%) does not belong to the recognized FCAZ zones (Figure 8a). This is an epicenter of the Ozernovskiy earthquake with $M=7.75$ in Koryakia, which occurred on 22 November 1969, in the north of the considered region.

In 2006 the Olyutorskoye earthquake occurred in Koryakia to the north of the border of the considered region, its magnitude was similar to the Ozernovskoye (Figure 8a). The missed target error of the Ozernovskoye earthquake and non-inclusion of the Olyutorskoye earthquake area in the considered region is caused by the fact that their epicenters are located outside of today's subduction zone. The conditions for the occurrence of these earthquakes outside of the subduction zone are dramatically different from the remaining considered strongest earthquakes in the region. This is also justified by the fact that the epicenters of both earthquakes lie outside of the territory in respect of which work is 
underway to make a long-term forecast of the strongest earthquakes using the method of Academician of RAS S.A. Fedotov [53]. Accordingly, the epicenter of the Ozernovskoye earthquake is possibly not a missed target error.

On the Pacific Coast of the Kuril Islands (Figure 8b), the epicenter of just one (9\%) out of 11 known earthquakes with $M \geq 7.75$ is a missed target error (the earthquake dated 1 May 1915, with $M=8.3$ ). Let us note here that the identification of the areas prone to earthquakes on the Pacific Coast of the Kuril Islands using pattern recognition methods has not been previously performed. It is undertaken in this paper for the first time.

It is noteworthy that the FCAZ zones recognized in the mountain belt of the South American Andes contain 69\% of earthquake epicenters with $M \geq 5.0$ from among those present in the instrumental catalog used for recognition purposes. That said, they occupy approximately half of the area of the seismically active mountain belt of the Andes and the active subduction zone. FCAZ zones on the Kamchatka coast contain $73 \%$ of the epicenters of earthquakes, with $M \geq 4.0$ among those present in the instrumental catalog and occupying $40 \%$ of the area of seismically active Kuril-Kamchatka and Aleutian Arcs falling within the boundaries of the considered region. On the coast of the Kuril Islands, FCAZ zones contain $81 \%$ of the earthquake epicenters with $M \geq 5.0$ among those present in the catalog. The aforesaid allows interpreting, with a high degree of reliability, the recognized FCAZ zones (Figures $7 \mathrm{~b}$ and 8 ) as the areas prone to earthquakes with $M \geq 7.75$ in the mountain belt of the Andes and on the Pacific Coast of the Kamchatka Peninsula and the Kuril Islands.

The recognized zones prone to the strongest earthquakes in Kamchatka and on the Kuril Islands are well aligned with the results of a long-term seismic forecast for IX 2013VIII 2018, using the method of Academician of RAS S.A. Fedotov. In [53], earthquakes with $M=5.7-7.2$ were expected throughout the Pacific Coast of Kamchatka with a varying probability level. That said, during the above-mentioned time interval, earthquakes with $M$ $\geq 7.7$ were expected in the coastal zone of the Avacha Bay and near the shores of Southern Kamchatka. Fairly big FCAZ zones are situated in these areas as well (Figure 8a).

The best justification for the reliability of recognition results is a pure experiment, i.e., the analysis of the alignment of FCAZ zones and the location of the epicenters of earthquakes (with $M \geq M_{0}$ ) that occurred after the end of the instrumental catalog used for recognition purposes. For instance, three earthquakes with $M \geq 7.75$ occurred in the mountain belt of the South American Andes after 2013: on 1 April 2014, with $M=8.2$ (northwest of the Chili coast), on 16 September 2015, with $M=8.3$ (Chili coast), and on 16 April 2016, with $M=7.8$ (Ecuador). Information about these strongest earthquakes was not used for recognition purposes in any manner whatsoever.

The epicenters of earthquakes of 2014, 2015, and 2016 are shown in Figure 7b using black, purple, and blue stars, respectively. The first two epicenters are located strictly inside the FCAZ zones. The third one is a short distance away from the boundaries of the recognized zones. This allowed obtaining an argument in favor of the reliability of the completed FCAZ recognition, both weighty and independent from research results.

Summarizing the results obtained, an important achievement should be noted. For the first time, the strongest earthquake-prone areas were successfully recognized based on the objective classification without involving morphostructural zoning and the formation of learning sets. That said, the results are generally well aligned with those previously obtained independently using the EPA method (for details, see below). Accordingly, it is shown that FCAZ method is applicable to the system observation of regions with a very high seismicity level.

\subsection{FCAZ Recognition of the Areas Prone to Strong and Significant Earthquakes for One and Several Threshold Magnitudes}

The regions with a lower seismicity level than in the previous section of the article: California, the Altai-Sayan region and the Baikal-Transbaikal region, the Caucasus, as well as the Crimean Peninsula, and the northwestern Caucasus are considered. The sets of recognition objects were formed based on the epicenters of crustal earthquakes 
from the following catalogs: ANSS (1960-2012, California), Earthquakes in the USSR and Earthquakes of Northern Eurasia (1962-2008, the Caucasus; 1962-2008, Crimea and northwestern Caucasus; 1962-2009, the Altai-Sayan region; and 1962-2010, the BaikalTransbaikal region). Based on the assessment of $M_{\mathrm{c}}$, it was decided to use the epicenters of earthquakes with $M \geq M_{R}=3.0$ (31,874 epicenters) as recognition objects in California [54-56]; in the Altai-Sayan region, $M \geq M_{\mathrm{R}}=2.8$ (3647 epicenters) [57]; in the Caucasus, $M \geq M_{R}=3.0$ (6980 epicenters) [21,22,58,59]; in Crimea and northwestern Caucasus, $M$ $\geq M_{R}=2.0$ (2398 epicenters) [60,61]; and in the Baikal-Transbaikal region, $M \geq M_{R}=2.7$ (11,297 epicenters) [35].

In Figure 9, the totality of green and red colors shows the recognized FCAZ zones prone to strong earthquakes in California $(M \geq 6.5)$ and significant earthquakes in the Altai-Sayan region $(M \geq 5.5)$, in the Caucasus $(M \geq 5.0)$, and in the Crimean Peninsula and northwestern Caucasus $(M \geq 4.5)$.

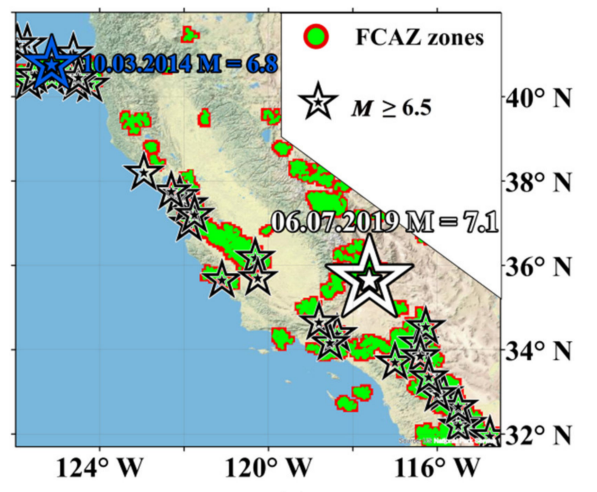

(a)

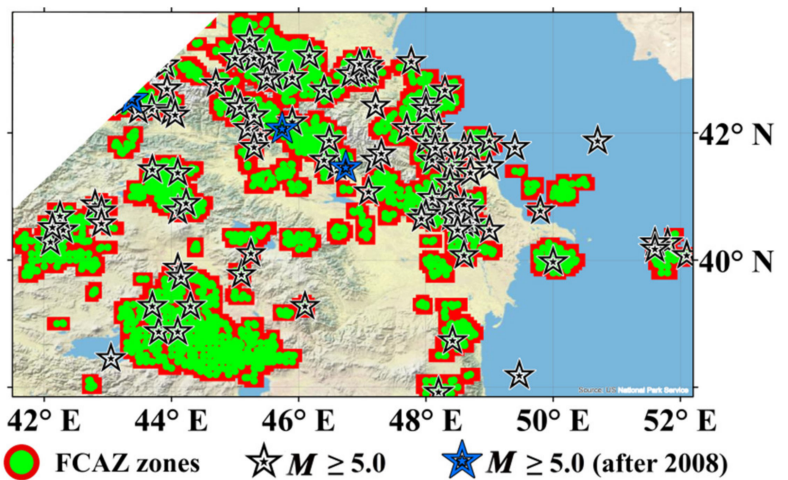

(b)

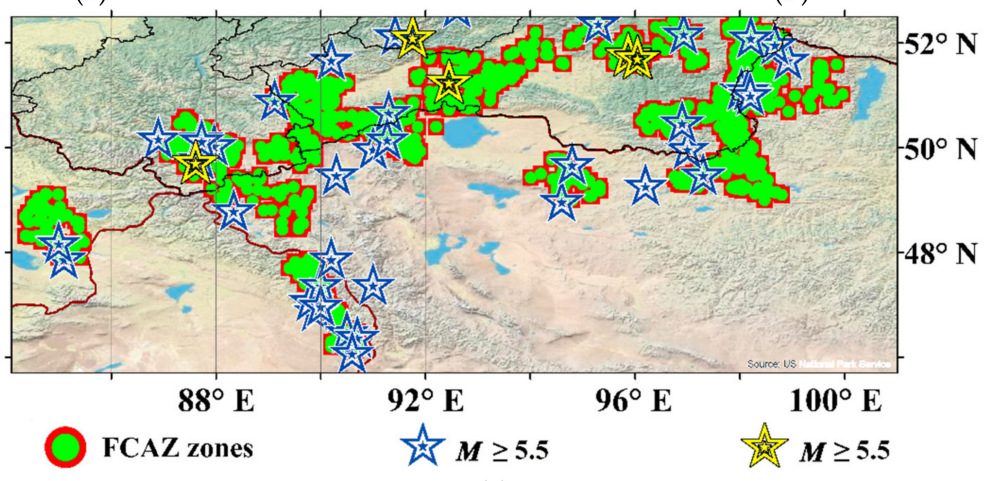

(c)

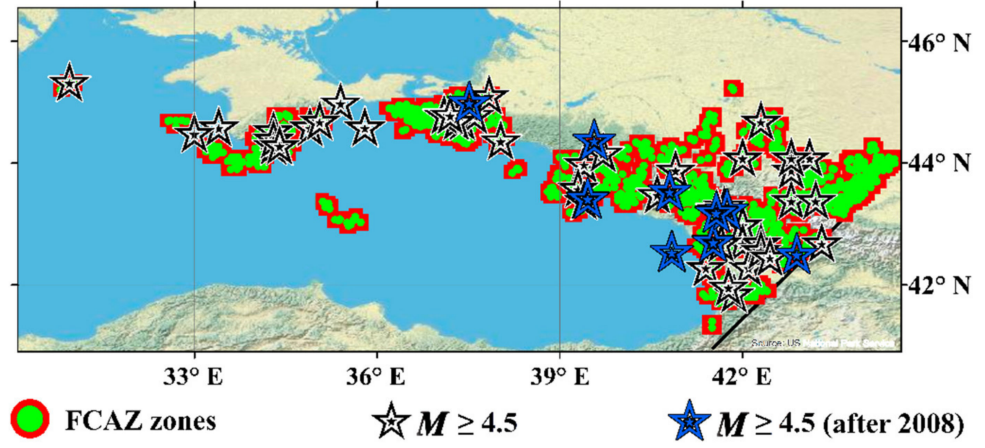

(d)

Figure 9. FCAZ zones prone to earthquakes: (a) California, $M \geq 6.5$ (black stars-epicenters of earthquakes with $M \geq 6.5$ from 1836 through 2010; blue and white stars- $M \geq 6.5$, since 2014); (b) the Caucasus, $M \geq 5.0$ (black stars- $M \geq 5.0$ for the period of 650-2008; blue stars- $M \geq 5.0$, since 2009); (c) the Altai-Sayan region, $M \geq 5.5$ (blue stars- $M \geq 5.5$ for the period of 1902-2008; yellow stars- $M \geq 5.5$, since 2011); (d) Crimea and the northwestern Caucasus, $M \geq 4.5$ (black stars-M $\geq 4.5$ for the period of 1900-2008; blue stars $-M \geq 4.5$, since 2009). 
At first sight, out of 33 strong earthquakes with $M \geq 6.5$ (1836-2010) in California, the epicenters of $5(15 \%)$ do not fall within the FCAZ zones (Figure 9a). It should be noted that three of them are located offshore in the Pacific Ocean at a great distance from the coast and are thus not caused by the tectonics of the studied region. Two other earthquakes occurred in 1857 and 1906 a long time before the commencement of systematized instrumental observations in the region. If thus these special cases are excluded from consideration, we will see that, in fact, the result contains no missed target errors [54].

It should be noted that in California, FCAZ zones contain $83 \%$ events with $M \geq 4.5$ among those present in the instrumental catalog. After the end of the catalog used to select recognition objects, two strong earthquakes occurred (Figure 9a). The epicenters of both lie strictly within the FCAZ zones. Accordingly, we have grounds to believe that recognition resulted in building sought areas prone to strong earthquakes with $M \geq 6.5$ in California.

In the Altai-Sayan region, out of 48 (1902-2008) significant earthquakes with $M \geq 5.5$, only 7 epicenters (15\%) are located outside of the recognized FCAZ zones (Figure 9c). It should be noted that 6 of them occurred before the commencement of active seismological observations. That said, 3 epicenters are situated in Mongolia, 2 are located in the south of the Krasnoyarsk region, where a small number of seismic stations now function.

FCAZ zones contain $67 \%$ of the earthquake epicenters with $M \geq 4.0$ from among those present in the catalog. After the end of the used instrumental catalog, five significant earthquakes occurred in the region (Figure 9c). Of them, four epicenters are located strictly inside FCAZ zones. Summing it up, the totality of provided arguments allows stating that the results of FCAZ recognition in the Altai-Sayan region shown in Figure $9 \mathrm{c}$ have a high degree of reliability [57].

In FCAZ research in the Altai-Sayan region, an attempt was also made to recognize zones with the lowest possible number of missed target errors. For this purpose, localization radius $r_{q}(W)$ was varied in DPS clustering through changes in a preset interval of values of parameter $q$. Of all obtained recognition variants, an optimal one was selected, i.e., having the lowest number of omissions of significant earthquake epicenters. This variant had two missed targets less than the main variant of FCAZ zones (Figure 9c).

The epicenters of these two significant earthquakes, which make up the difference in the number of missed target errors, are located within and at the border of Mongolia. That said, the resulting area of optimal zones was 1.5 times higher than in the main recognition variant (Figure 9c). Accordingly, in the case of optimal FCAZ zones, the number of false alarms grows inevitably, adversely affecting the reliability of recognition. In this regard, the final choice was made in favor of the main recognition variant (Figure 9c) [57].

In the Caucasus, out of 106 (650-2008) significant earthquakes with $M \geq 5.0$, the epicenters of $8(7.5 \%)$ are located outside of FCAZ zones (Figure $9 \mathrm{~b}$ ). Explaining these missed targets, note that three earthquakes occurred in 957, 1250, and 1667 long before the commencement of systemized instrumental observations in the region. Three more unrecognized epicenters are situated at a great distance from seismic networks based on which the catalogs used for recognition were created. This casts doubt on the fact that these earthquakes are real missed targets. Accordingly, certain missed targets are two epicenters of significant earthquakes.

It should be noted that FCAZ zones contain $68 \%$ of the epicenters of earthquakes with $M \geq 4.0$ among those present in the instrumental catalog. The epicenters of all three significant earthquakes which occurred after the end of the used instrumental catalog are located strictly inside of FCAZ zones (Figure 9b). This is an argument in favor of the reliability of the FCAZ recognition results [22].

It should be noted that the subregion in the northwestern part of the Caucasus (white triangle in Figure 9b) was excluded from consideration due to the lack of earthquake epicenters representing recognition objects in this region. FCAZ recognition in this subregion turns out to be impossible. This area forms part of the united region Crimea-northwestern Caucasus, in which FCAZ recognition was performed for $M_{0}=4.5$ [21]. 
The number of earthquakes with $M \geq M_{0}$ must be sufficient to assess the level of their alignment with the recognized FCAZ zones. In the instrumental catalog of earthquakes of the Crimea and northwestern Caucasus region, there are just 5 events with $M \geq 5.0$ and 17 , since 1900 . That said, the magnitudes of earthquakes of the early 20 th century can be overstated. For that reason, two different magnitude thresholds of the earthquake locations being recognized $M_{0}=4.5$ and $M_{0}=5.0$ were considered in the region.

As can be seen from Figure 9d, FCAZ zones are well aligned with the location of the epicenters of significant earthquakes (1900-2008) with $M \geq 4.5$. Only 5 (11.4\%) out of 44 epicenters are situated outside of recognized zones. It should be noted that all missed earthquakes occurred before the commencement of the used instrumental catalog. That said, 3 earthquakes have magnitudes $M=4.5-4.7$ identified to a precision of \pm 0.5 . For the threshold $M_{0}=4.5$, it is fairly safe to say that there are only two missed targets. FCAZ zones contain $67 \%$ of the earthquake epicenters, with $M \geq 3.5$ among those present in the catalog.

The recognized FCAZ zones (Figure 9d) turn out to be connected with the events of higher magnitude threshold $M_{0}=5.0$. At the moment of recognition, there are 17 known earthquakes with $M \geq 5.0$ in the region. The epicenters of $15(88.2 \%)$ of them are located within or at the boundaries of FCAZ zones. Accordingly, if we consider earthquakes with $M \geq 5.0$, then FCAZ zones can be interpreted as areas prone to the same events. That said, two missed targets are the same two Black Sea earthquakes as in the previous reasoning about the threshold $M_{0}=4.5$.

Nine earthquakes with $M \geq 4.5$ occurred in the considered region after the end of the used instrumental catalog. The epicenters of eight of them lie strictly within FCAZ zones. The only missed target error is the epicenter of the earthquake, with $M=4.6$ located offshore in the Black Sea.

The considered Crimea-Caucasus region is the first one for which FCAZ zones were interpreted for two different magnitude thresholds. In other words, in the recognition problem of the areas prone to earthquakes, there was variation in the magnitude threshold $M_{0}[60]$.

The above statistical data allows, to a great extent of reliability, interpreting FCAZ zones (Figure 9) as the areas prone to strong earthquakes in California and the areas prone to significant earthquakes in the Altai-Sayan region, the Caucasus, as well as in the Crimean Peninsula and the northwestern Caucasus.

The description of the first-ever successive recognition of the areas prone to earthquakes for several magnitude thresholds in the same region is given further. This recognition was performed using the SFCAZ method mentioned above, which further develops FCAZ. Successively studied were the areas prone to earthquakes with $M \geq 5.5, M \geq 5.75$, and $M \geq 6.0$ in the Baikal-Transbaikal region [35].

Phase one of the research entailed the solution of a classical problem of recognizing the areas prone to significant earthquakes $\left(M \geq M_{0}=5.5\right)$. Figure 10a shows the recognized zones that are well aligned with the earthquake epicenters with $M \geq 5.5$. Out of 71 such earthquakes, the epicenters of two $(2.8 \%)$ are located outside of recognized zones, thus creating missed target errors. These two earthquakes occurred before the commencement of active instrumental observations in the region (1929 and 1957) and have a magnitude $M=5.6$, identified to a precision of \pm 0.5 [52], and their epicenters are located outside of the Russian Federation. Accordingly, their actual magnitude can be lower than the threshold $M_{0}=5.5$ and the completed recognition is likely to have no missed targets.

Totally new are the second and third phases of successive recognition. Phase two entailed studying the areas prone to significant earthquakes with $M \geq 5.75$ in the same Baikal-Transbaikal region. To that end, only the epicenters that were included in DPS clusters during phase one were used as recognition objects. Accordingly, inside the DPS clusters that define high seismicity zones for $M \geq 5.5$, subclusters and morphogenetic areas prone to stronger significant earthquakes were recognized. 


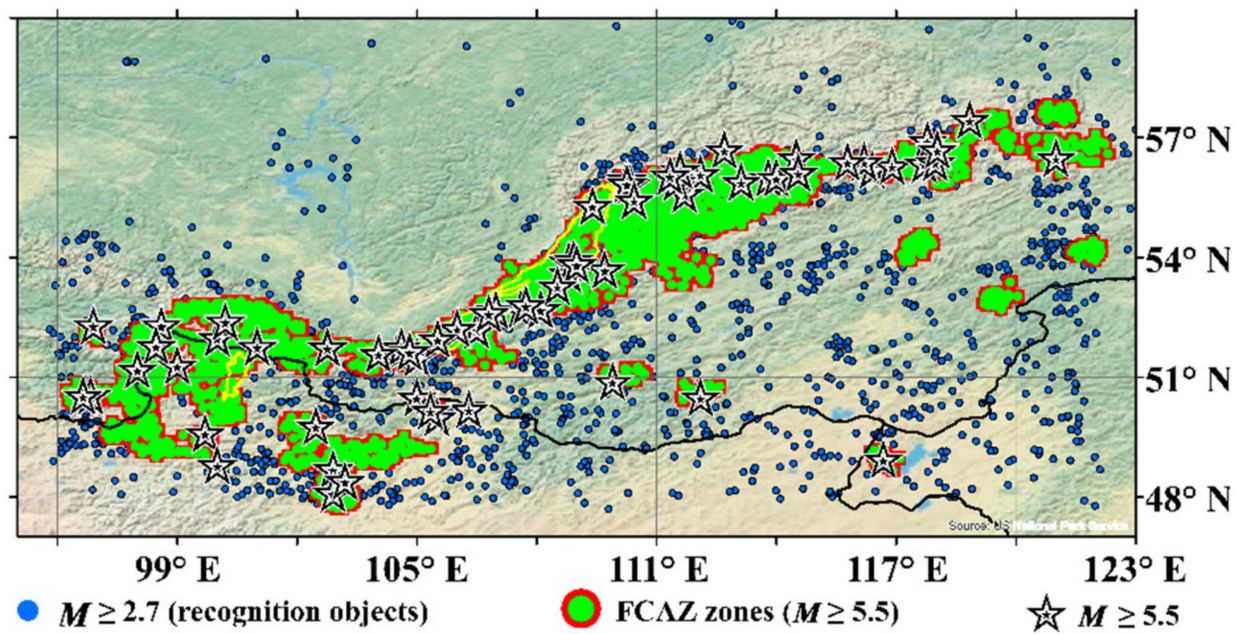

(a)

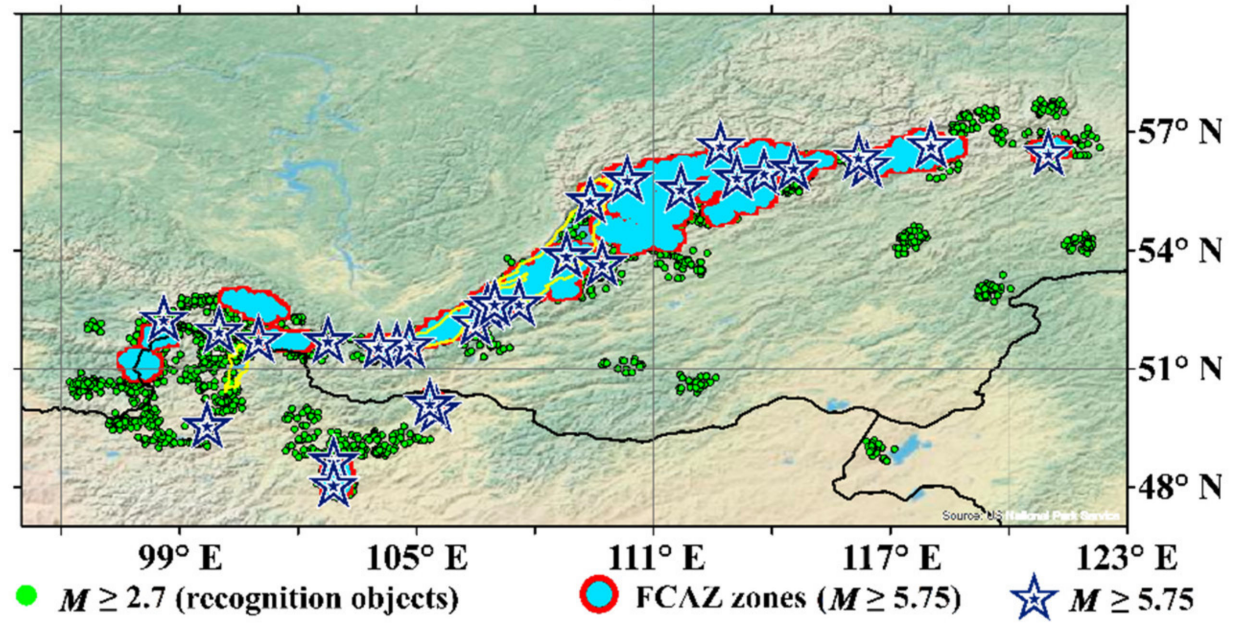

(b)

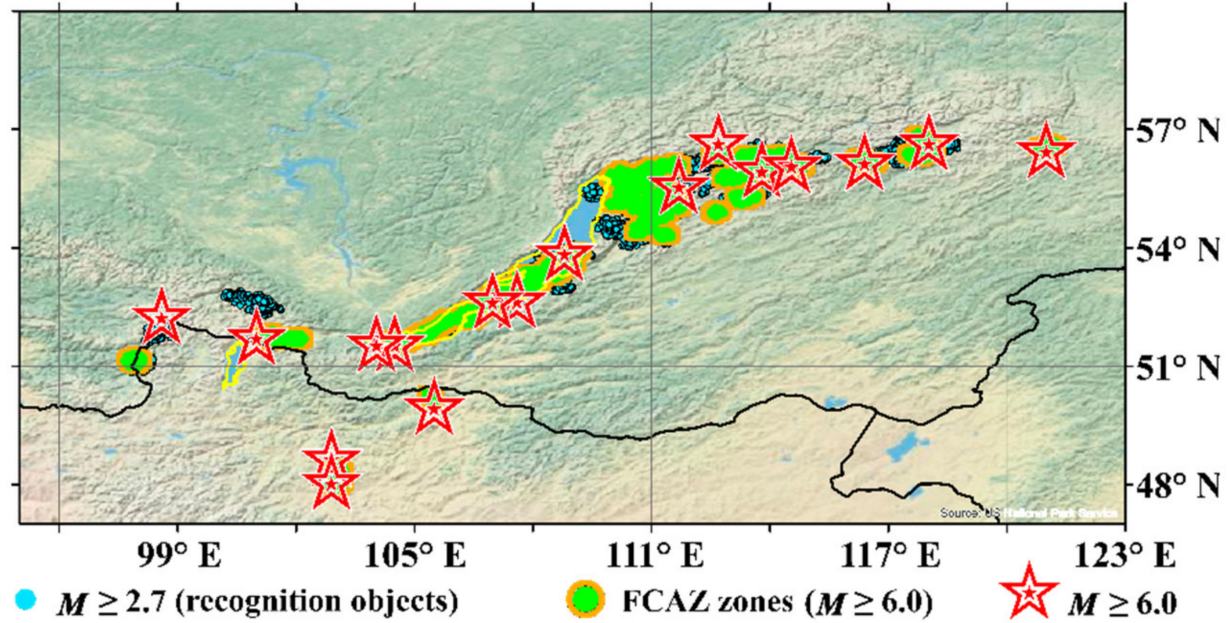

(c)

Figure 10. Baikal-Transbaikal region: (a) zones prone to earthquakes with $M \geq 5.5$ and the epicenters of earthquakes with $M \geq 5.5$; (b) zones prone to earthquakes with $M \geq 5.75$ and the epicenters of earthquakes with $M \geq 5.75$; (c) zones prone to earthquakes with $M \geq 6.0$ and the epicenters of earthquakes with $M \geq 6.0$.

The zones recognized in this way are well aligned with the earthquake epicenters with $M \geq 5.75$ (Figure 10b). The epicenters of just $3(10 \%)$ of 30 such significant earthquakes lie 
outside of their boundaries. These are the epicenters of earthquakes with a fairly inaccurate identification of magnitude: $M=5.8 \pm 0.5$ and $M=5.8 \pm 0.2$ [52]. The magnitude of the third earthquake was recalculated from the energy class. The magnitudes of these three earthquakes are highly likely to have the values of $M<5.75$, and the earthquakes themselves are highly unlikely to constitute the subject matter of research. It should be noted that the recognized territories form part of high seismicity zones for the magnitude threshold $M_{0}=5.5$, identified during phase one of the research.

Phase three entailed recognizing the areas prone to strong earthquakes with $M \geq 6.0$. The epicenters of earthquakes included in the DPS clusters during phase two have already been used as recognition objects. Out of 17 earthquakes with $M \geq 6.0$, the epicenters of just two $(11.7 \%)$ are located outside of recognized zones (Figure 10c). The first one is the epicenter of the 1939 earthquake with $M=6.0 \pm 0.3$ [52]; the second one which occurred in 2008 , with $M=6.3$, is located at the distance of $0.15^{\circ}$ of the mapped zones.

After 2010, 3 earthquakes with $M \geq 5.5$ occurred in the considered region. The epicenters of two of them lie strictly within the zones corresponding to their magnitudes, which is an argument in favor of the reliability of SFCAZ recognition results.

Successive recognition using the SFCAZ method made it possible to obtain a chain of high seismicity areas, in which the zones for greater threshold magnitudes are inserted in the relevant zones for smaller ones. Accordingly, the results of successive recognition can be used in practical seismic zoning. The results of completed successive recognition allow us to argue that the performed transition from FCAZ to SFCAZ does not impair the quality of obtained results [35].

After the end of the used instrumental catalogs, 22 earthquakes with $M \geq M_{0}$ occurred in 5 considered regions. These events allowed conducting a pure experiment. It should be noted that 19 epicenters $(86.3 \%)$ are located within high seismicity zones. Such a result of a pure experiment should be recognized as successful. This yielded an objective argument in favor of result reliability for completed FCAZ recognition.

The earthquake with $M=7.1$, which occurred in California on 6 July 2019 (white star in Figure 9a), deserves a separate mention. The epicenter of this earthquake is located inside FCAZ zones in the territory with no prior strong earthquakes. It should be noted that this epicenter is located outside of the zones recognized by the EPA method [62].

\section{Discussion}

\subsection{Justification of Reliability of FCAZ Recognition Results}

Simultaneously with the pure experiment (see above) or in the absence of the same, reliability was assessed based on the computational control experiments. FCAZ recognition employs two types of control experiments-individual seismic history and complete seismic history.

In the individual seismic history experiment, FCAZ zones are constructed based on findings from the DPS clustering of the earthquake epicenters (with $M \geq M_{R}$ ) only for 20 years preceding the events with $M \geq M_{0}$. The experiment ends with an analysis of the relative position of the recognized zones and the epicenter of the earthquake with $M \geq M_{0}$, for which the zones were constructed.

The complete seismic history experiment excludes from the used instrumental catalog the epicenters for the past few years during which events with $M \geq M_{0}$ have occurred. FCAZ zones are recognized through the use of DPS clustering of the epicenters remaining in the catalog. The experiment ends with an analysis of the location of the earthquake epicenters with $M \geq M_{0}$ from the discarded part of the catalog relative to the recognized FCAZ zones.

It should be noted that to improve the objectivity of computational experiments, they are conducted using the same values of the FCAZ method parameters $(q, \beta, \delta, \omega, v, C)$ (i.e., the DPS and $E^{2} X T$ algorithms) as for the main recognition variant. The values $\beta, \omega$, and $v$ in the main recognition variant (see above) were computed in an automated manner by the artificial intelligence blocks [21]. 
Series of control experiments were conducted for the mountain belt of the South American Andes, the Pacific Coast of the Kamchatka Peninsula, California, and the Caucasus. Figure 11 shows typical results of experiments in California as an example.

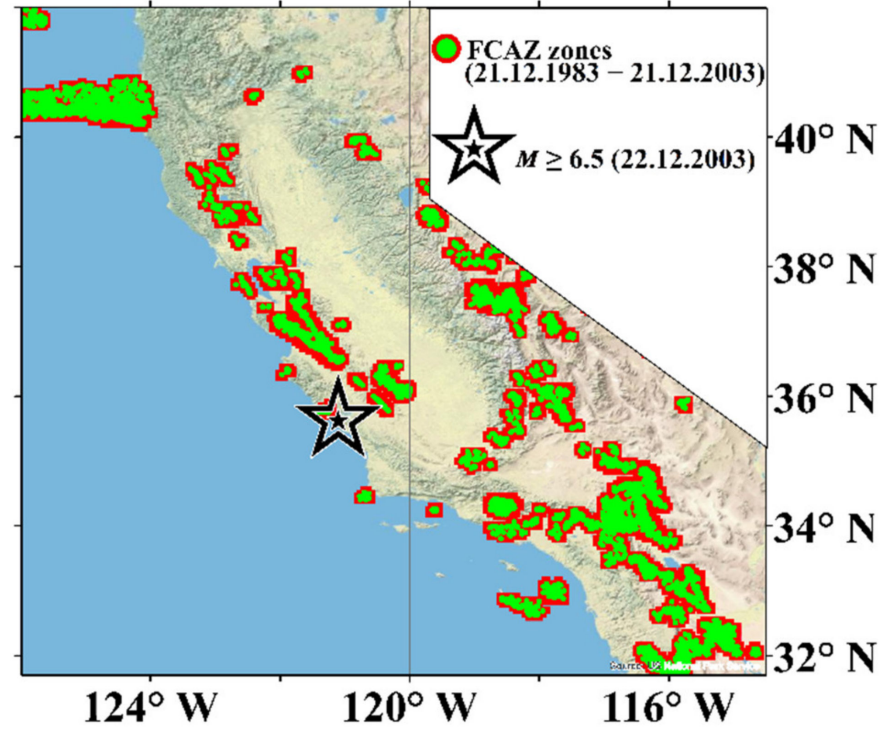

(a)

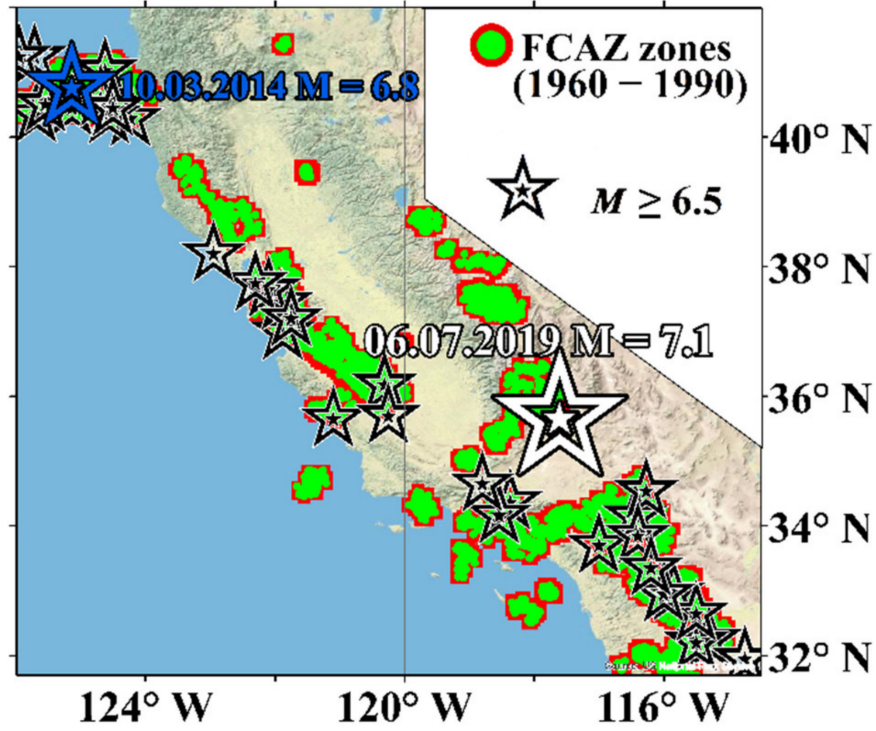

(b)

Figure 11. California: (a) computational individual seismic history experiment for the earthquake dated 22 December 2003 ; (b) computational complete seismic history experiment (1960-1990) and the epicenters of earthquakes with $M \geq 6.5$.

A comparative analysis of the spatial location of 29 FCAZ zones recognized in the individual seismic history experiments and the main results of FCAZ recognitions (see above) demonstrated a high degree of their similarity. That said, the epicenters of 27 out of 29 earthquakes involved in the experiments are located inside or at the boundaries of the recognized zones.

The FCAZ zones recognized in the course of complete seismic history experiments in terms of their forms and spatial location are close to the FCAZ zones of the main recognition variants. The zones include 25 out of 27 epicenters of earthquakes with $M \geq M_{0}$, which occurred years later (in particular, 10-25 years) after the date of the last recognition object (earthquake epicenter). For instance, in California, the epicenter of the earthquake with $M=7.1$ (white star in Figure 11b), which occurred 28.5 years after the end of the catalog used in the experiment is located strictly inside FCAZ zones.

The results of control experiments demonstrate the stability of FCAZ recognition in time and space. This confirms the reliability of the main recognition variants in the studied regions as the zones prone to the strongest, strong, and significant earthquakes.

A comparative analysis of FCAZ zones and the EPA zones recognized earlier [4,62-64] was conducted in the mountain belt of the Andes, on the Pacific Coast of Kamchatka, in California, and the Caucasus. FCAZ zones typically occupy a smaller area than EPA zones. An exception is the mountain belt of the Andes, where FCAZ recognition covered a larger area. Figure 12 shows the comparison of FCAZ zones and EPA zones in Kamchatka and California.

In Kamchatka, high seismicity territories identified by both methods have a common, northeastern strike due to the subduction zone (Figure 12a). That said, FCAZ zones are typically located northwest of EPA zones. This is because most objects recognized as high seismicity ones using the EPA method were formed by the intersection of a deep-water trench with the morphostructural lineaments of rank II and III. At the same time, the main part of the epicenters that represent FCAZ recognition objects are located in the Benioff zone (seismic focal zone) within the continental slope before the trench and are generated by the convergent interaction of two lithospheric plates. 
The FCAZ zones are well aligned with the epicenters of known strongest (the Andes and Kamchatka), strong (California), and significant (the Caucasus) earthquakes. A check of this kind of alignment for EPA zones is not a clearly formulated objective. The reason is the construction peculiarities of morphostructural zoning scheme and the selection of EPA recognition objects, especially in the Pacific Seismic Rim regions. Moreover, EPA has no formalized transition from the classification of point objects to sought flat high seismicity zones with unambiguous boundaries. EPA solves this nontrivial problem by the trivial construction of circles with a radius proportionate to the magnitude of recognized earthquakes around the objects classified as high seismicity ones. Circles coincide with the areas initially used to compute the values of characteristics of the objects. The reasonableness of such transition is not obvious.

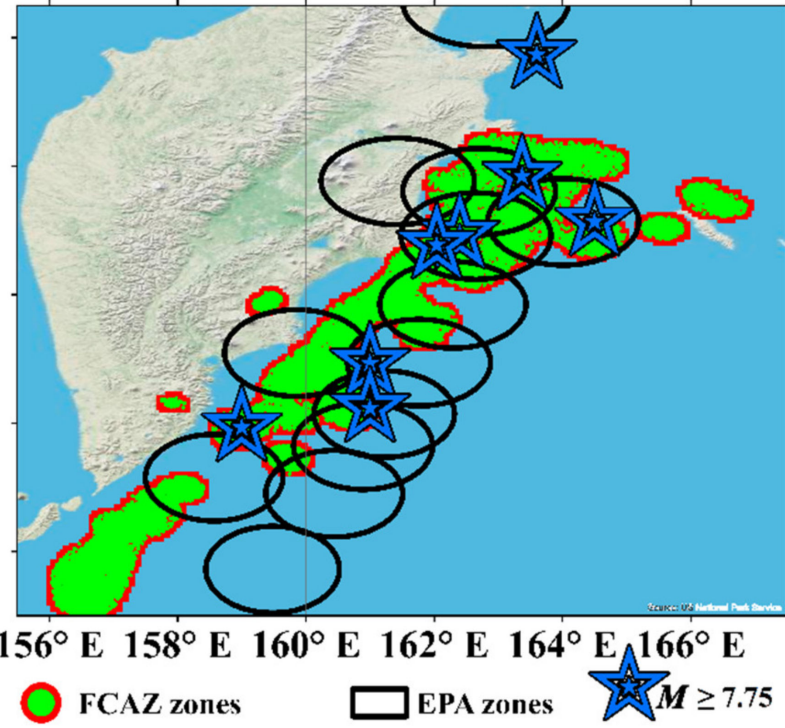

(a)
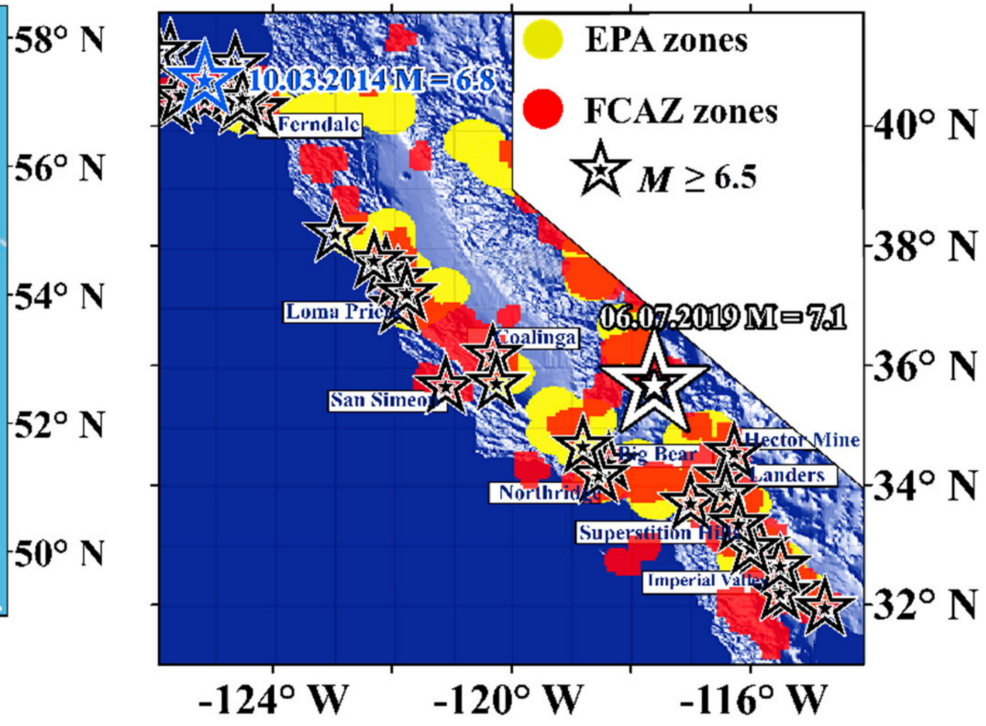

(b)

Figure 12. Comparison of the zones prone to earthquakes recognized by FCAZ and EPA methods: (a) Pacific Coast of the Kamchatka Peninsula; (b) California.

As regards the events with $M \geq M_{0}$, which constitute the material for pure experiment for both methods (FCAZ and EPA), seven out of eight epicenters of such earthquakes are located inside or at the boundaries of FCAZ zones. That said, only four epicenters are guaranteed to be located inside the EPA zones. It should be noted that the epicenter of the earthquake dated 6 July 2019, with $M=7.1$ in California is situated strictly inside the FCAZ zones, yet outside of the EPA zones. Summing it up, it is safe to say that the result of FCAZ recognition offers a whole range of benefits as compared with EPA results.

To ascertain the contribution of foreshock and aftershock sequences to the formation of the final result of FCAZ recognition, for the first time, epicenters from declustered catalogs were used as recognition objects. On the Pacific Coast of the Kamchatka Peninsula and in California, the FCAZ zones recognized based on complete and declustered catalogs turned out to be almost coinciding. This evidences that for the considered regions the existence of foreshock and aftershock sequences in the catalogs does not have a significant impact on the results of recognition of high seismicity areas as part of the FCAZ clustering method.

The optimal values of the parameter $\beta$ computed automatically (the maximality of density in the DPS clusters, and in fact, the algorithm's "look" at the topology of the set of recognition objects and the separability of their dense condensations from the loose complement) for both recognitions in Kamchatka turned out to be very close: -0.2 and -0.2 for the declustered catalog; -0.15 and -0.2 for the complete catalog. Similar optimal values $\beta$ in California are different. This can be explained by the fact that after a declustering of the catalog, the number of recognition objects went down by $68 \%$, causing a change in the 
quantitative-spatial distribution of the set of objects. At the same time, the experiment in California can also be treated as successful since the results show that declustering a set of FCAZ recognition objects has not led to a significant change in either the DPS clusters or, in fact, the FCAZ zones [65].

\subsection{FCAZ Recognition as the Problem of Advanced Systems Analysis}

The FCAZ recognition problem is considered from the standpoint of advanced systems analysis [e.g., https: / / siiasa.ac.at/ access date: 30 July 2021]. The process and result of identification of potentially high seismicity hazard zones represent a complicated system [66]. The condition of the system depends on both spatial coordinates of recognition objects and on time. The results of FCAZ recognition obtained above follow from the algorithmic analysis of the currently identified objects $W=\{w\}$, which represent numerous epicenters of, generally speaking, fairly weak earthquakes.

For today, FCAZ performed a reliable recognition of sought high seismicity areas in several mountainous countries. Substantiations of such reliability are given for a certain period. This period is not long enough in both geological and real-time. In practice, it means tens, maximum hundreds of years. This period is characterized by the fact that a set of objects $w \in W$ does not change drastically throughout the period. Here, a drastic change means not only the emergence of the clouds of new epicenters of earthquakes with $M \geq M_{\mathrm{R}}$ in previously aseismic areas but also significant alteration of the object distribution topology.

Let $\Delta t$ be a time interval during that the set $W$ did not undergo any drastic changes. It is natural to assume that the FCAZ result obtained at the moment $t_{1}$ will take place until the moment $t_{2}=t_{1}+\Delta t$. Since $t_{2}$, the set $W$, has significantly changed its spatial form and/or topology. Consequently, at the moment $t_{2}$ it is necessary to perform a new FCAZ recognition taking into account the newly received initial data.

Treating this reasoning as the first step of the induction process also makes it easy to determine $\Delta_{i} t$ and the succession of the pairs:

$$
\left\{\left(t_{i}, \operatorname{FCAZ}\left(t_{i}\right)\right): i=1,2, \ldots\right\},
$$

where time values $t_{i}$ are the moments when FCAZ recognitions are repeated.

It should be noted that generally speaking, $\Delta_{i} t \neq \Delta_{j} t, \forall i, j=1,2, \ldots, i \neq j$ studying the dependence of $\Delta_{i} t$ on changes to the set $W$ over time represents an independent nontrivial problem of systems analysis, which falls beyond the scope of this paper.

Accordingly, an analytical approach to the recognition of potentially high seismicity areas as a complex system that changes over time, even though stable over fairly long local intervals, was created in the present paper. The approach is based on the dynamic changes of the principal parameters of the system. The latter justifies the attribution of algorithmic succession $T(i) \times$ FCAZ, where $T=\left\{t_{i} ; i=1,2, \ldots\right\}$ is defined by the formula (18), to systems analysis methods. The general scheme of this method is illustrated in Figure 13, where $\mu_{i}$ is the measure of recognition quality at the moment $t_{i}$.

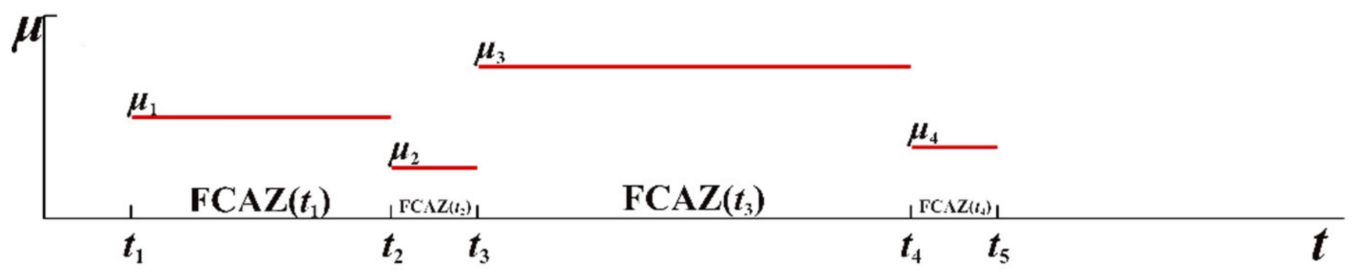

Figure 13. Illustration of the systems analysis method developed based on FCAZ recognition. Deep red color shows the values of the FCAZ recognition quality measure at different time intervals.

Let FCAZ $\gamma_{\gamma_{1}}\left(W_{t_{1}}\right): G=B_{t_{1}} \amalg H_{t_{1}}$ be the result of FCAZ recognition $\left(M \geq M_{0}\right)$ at the moment $t_{1}$. That said: 
- $W_{t_{1}}=\{w\}$ is the finite set of recognition objects (the epicenters of earthquakes with $\left.M \geq M_{\mathrm{R}}\right)$ at the moment $t_{1},\left|W_{t_{1}}\right|=n_{t_{1}}$;

- $G=\{g\}$ denotes certain coverage of the considered region by square objects, on which the $\mathrm{E}^{2} \mathrm{XT}$ algorithm works;

- $\gamma_{1}=\{\delta, C, \omega, v, q, \beta\}$ is a set of values of free parameters of FCAZ selected for an optimal recognition at the moment $t_{1}$;

- $\quad B_{t_{1}} \subset G$ and $H_{t_{1}} \subset G$ are the subsets of objects $g \in G$ classified as high seismicity and low seismicity ones, respectively, i.e., the objects $g \in B_{t_{1}}$ are fairly close, and the objects $g \in H_{t_{1}}$ are fairly distant from known and potential areas prone to strong earthquakes, $B_{t_{1}} \cup H_{t_{1}}=G, B_{t_{1}} \cap H_{t_{1}}=\varnothing$.

Let $B_{0, t_{1}}$ denote the set of epicenters of strong earthquakes that had occurred by the moment $t_{1}$. It is obvious that the higher the value of the inclusion measure of epicenters $B_{0, t_{1}}$ in the subset of high seismicity objects $B_{t_{1}}$, the better FCAZ recognition at the moment $t_{1}$ :

$$
\mu\left(B_{0, t_{1}} \subset B_{t_{1}}\right)=\left|B_{0, t_{1}} \cap B_{t_{1}}\right| /\left|B_{0, t_{1}}\right| .
$$

The quality of the FCAZ recognition problem considered above is determined by the fact that the results of future (after the appearance of new objects with time) expansions $\operatorname{FCAZ}_{\gamma}\left(W_{t}\right): G=B_{t} \amalg H_{t}$ tend to the limit characterized by the condition:

$$
\lim _{t \rightarrow \infty} \mu\left(B_{0, t} \subset B_{t}\right) \rightarrow 1
$$

Let us assume by the moment $t_{2}=t_{1}+\Delta t Z_{t_{1}, t_{2}}$ more strong earthquakes occurred, $B_{0, t_{2}}=B_{0, t_{1}} \cup Z_{t_{1}, t_{2}}$, i.e., bringing their total number to $\left|B_{0, t_{2}}\right|=\left|B_{0, t_{1}} \cup Z_{t_{1}, t_{2}}\right|$. That said, the total number of occurring earthquakes with $\mathrm{M} \geq \mathrm{M}_{\mathrm{R}}$ among the recognition objects increased by $z_{t_{1}, t_{2}}$ to a total of $n_{t_{2}}=n_{t_{1}}+z_{t_{1}, t_{2}}$. Let us denote this new set of objects $W_{t_{2}}=\{w\}$. In this new situation, at the moment $t_{1}+\Delta t$ we have important additional information in place, which was not available to us at the moment $t_{1}$. Accordingly, it is necessary to perform FCAZ recognition this time based on $W_{t_{2}}$ to obtain the expansion $\mathrm{FCAZ}_{\gamma_{2}}\left(W_{t_{2}}\right): G=B_{t_{2}} \amalg H_{t_{2}}$ (Figure 13).

FCAZ recognition is determined by the selection of free parameters $\gamma=\{\delta, C, \omega, v, q, \beta\}$. The parameters of the $\mathrm{E}^{2} \mathrm{XT}$ algorithm, as well as its result, directly depend on the recognized DPS clusters. In turn, $\beta$ in DPS is the maximality level of density of DPS clusters, which depends on the spatial arrangement of objects. Due to the earthquakes with $M \geq M_{R}$, which occurred over the time $\Delta t=t_{2}-t_{1}$, the spatial distribution of objects $w \in W_{t_{2}}$ will differ from the distribution of objects $w \in W_{t_{1}}$. For this reason, the selection of values $\gamma_{2}=\{\delta, C, \omega, v, q, \beta\}$ for FCAZ $\gamma_{\gamma_{2}}\left(W_{t_{2}}\right): G=B_{t_{2}} \amalg H_{t_{2}}$ must be performed by the above-mentioned artificial intelligence blocks. These blocks ensure the selection of optimal values of input parameters accounting the spatial distribution of recognition objects at a given moment in time.

It is clear that the spatial distribution of a set of objects $W_{t_{2}}$ can be so dramatically different from the spatial distribution of $W_{t_{1}}$ that $B_{t_{1}}$ will not be a proper subset $B_{t_{2}}$. In other words, the threshold (20) can fail to be achieved. To prevent this kind of situation and create a successive monotonous growing of FCAZ zones as the high seismicity areas recognized at the moment $t_{2}$, the integration of the zones $B_{t_{1}}$ and $B_{t_{2}}$ should be taken, i.e., $B_{t_{2}}=B_{t_{2}} \cup B_{t_{1}}$.

FCAZ recognition in the subsequent moments in time $t_{k}=t_{k-1}+\Delta t, k=3,4, \ldots$ is constructed similarly following the process of induction.

Based on the FCAZ results presented in this paper, the moment in time when control experiments were conducted (e.g., complete seismic history), for any of the studied regions is fixed as $t_{1}$. Then $t_{2}$ is the moment for which the main result of FCAZ recognition was obtained. Then the comparison of sets of recognition objects and FCAZ zones at the moments $t_{1}$ and $t_{2}$ allows concluding that in respect of all regions considered over the time intervals $\Delta t=t_{2}-t_{1}$, the sets of objects $w \in W$ did not undergo any drastic change. Accordingly, given such fixed $t_{1}$ and $t_{2}$, the moment $t_{2}$ is not yet time for the performance 
of new FCAZ recognition taking into account new initial data. In this situation, pure examination and computational control experiments gain special importance.

Similarly, the time has not yet come for new FCAZ recognition either if we take $t_{1}$ as the moments for which the main results of FCAZ recognition are obtained and take as $t_{2}$, for instance, the year 2021.

\section{Conclusions}

The problem of recognition of the areas prone to strong (with $M \geq M 0$ ) earthquakes $[4,5,67,68]$ is studied in this paper using two methods developed by the authors. Their fundamental difference lies in the selection of recognition objects.

In the first method, objects are vicinities of intersections of lineament axes constructed using a formalized technique of morphostructural zoning. In the second method, objects are constituted by the epicenters of all earthquakes that meet the condition $M \geq M R$, where threshold MR is significantly lower than the magnitude threshold M0 of the recognized earthquake areas.

The methods also differ in the sets of characteristics of object description and the employed pattern recognition algorithms. In the first case, these are geological-geophysical and geomorphologic characteristics and the original Barrier-3 algorithm. In the second case, these are the characteristics of epicenters of weak earthquakes and systems analysis procedure for the objective recognition of dense condensations of FCAZ.

Despite the critical differences between these two original methods, their recognition results are well aligned in the Altai-Sayan-Baikal region and the Caucasus. The territories classified as high seismicity ones by both methods should be viewed as the most hazardous since they are recognized as such by independent methods based on different recognition objects and their characteristics.

The first method allows, from the standpoint of dynamic systems analysis, repeatedly solving the problem of classification of lineament intersections into high and low seismicity ones. This relies on the fact that learning is every time performed only for one high seismicity class, which is easy to form with due regard for new strong earthquakes that have occurred. This, in turn, contributed significantly to the development of the classical EPA approach towards the recognition of high seismicity areas [3-5,67,69,70].

Previously, there was a problem of identification of the learning set of the objects in whose vicinities strong earthquakes cannot occur. This problem is solved in the paper by developing an original method for image recognition called Barrier-3.

This algorithm makes it possible to classify objects into high and low seismicity based on one learning class. Barrier-3, having information about the objects with known epicenters of earthquakes with $M \geq M 0$ in their vicinities, enables finding a set of the so-called similar objects.

The recognition of the areas prone to earthquakes is the first developed method to rely on the hypothesis about the association of epicenters of strong earthquakes with the intersections of morphostructural lineaments, which was confirmed in [18]. Accordingly, building the morphostructural zoning map is an important phase of the first method for studying the problem. That said, despite the logical formalization conducted as early as 1977 by a group of mathematicians under the guidance of I.M. Gelfand, the process of morphostructural zoning remains ambiguous. In this regard, a question was pending: Can the recognition of strong earthquake-prone areas be performed without constructing morphostructural zoning model? [22]. This paper answers this question positively based on the use of the systems analysis method FCAZ.

The employment of DMA algorithms in this paper, which use the epicenters of earthquakes as recognition objects, justifies this positive answer. Accordingly, the system FCAZ approach is a new step in the study of a recognition problem of strong earthquake-prone areas.

The recognition process of the high seismicity hazard zones in tectonically active regions represents a complicated system. The condition of the system depends on both spatial coordinates of recognition objects and on time. In this regard, FCAZ recognition is viewed 
in this paper from the perspective of the systems analysis. The system-mathematical model of FCAZ recognition as a complicated dynamic system was developed. The space-andtime model T(i) $\times$ FCAZ for recognition of the areas prone to the strongest, strong, and significant earthquakes makes it possible to develop a schedule of subsequent iterations for the recognition of high seismicity hazard zones for the regions studied in this paper.

The following regions with varying seismicity levels were studied by Barrier-3 and FCAZ methods in this paper:

- Barrier-3-the Altai-Sayan-Baikal region $(M \geq 6.0)$ and the Caucasus $(M \geq 6.0)$.

- $\quad$ FCAZ-mountain belt of the South American Andes $(M \geq 7.75)$, the Pacific Coast of the Kamchatka Peninsula $(M \geq 7.75)$, and the Kuril Islands $(M \geq 7.75)$; California $(M \geq 6.5)$; the Baikal-Transbaikal region $(M \geq 5.5, M \geq 5.75, M \geq 6.0)$; the Altai-Sayan region $(M \geq 5.5)$; the Caucasus $(M \geq 5.0)$; the Crimean Peninsula and northwestern Caucasus $(M \geq 4.5, M \geq 5.0)$.

The Altai-Sayan-Baikal region, the Pacific Coast of the Kuril Islands, and the Crimean Peninsula were first studied with the employment of methods for the recognition of earthquake-prone areas. Moreover, the Baikal-Transbaikal region was used as an example of the first recognition of earthquake-prone areas for the finite succession of growing magnitude thresholds $M_{0}^{1}<M_{0}^{2}<M_{0}^{3}$. The joint presentation of the recognition results obtained by the Barrier- 3 and Cora- 3 algorithms in the Caucasus based on their composition with a fuzzy set allowed halving the number of missed targets.

It was shown, using California and the Pacific Coast of the Kamchatka Peninsula as an example, that the existence of foreshock and aftershock sequences in the catalogs of earthquakes does not have a significant impact on the FCAZ recognition results. A totality of control experiments conducted in this paper demonstrates the reliability and reproducibility of the interpretation of FCAZ zones as the areas prone to the strongest, strong, and significant earthquakes.

In the studied regions, FCAZ zones occupy a relatively small area as compared with the total seismicity field, which makes up $30 \%-40 \%$ of the total seismicity space and $50 \%-65 \%$ of the space where earthquakes with $M \geq M_{\mathrm{R}}$ occur. This illustrates the spatial nontriviality of the obtained results.

Findings from the paper also demonstrate that low seismicity can actually "manifest" the properties of geophysical fields, which in the classical EPA approach are used directly as the characteristics of recognition objects.

Author Contributions: Conceptualization, B.A.D. and A.D.G.; data curation, B.A.D.; formal analysis, B.A.D., A.D.G., and S.M.A.; funding acquisition, B.A.D.; investigation, B.A.D. and A.D.G.; methodology, B.A.D., A.D.G., and S.M.A.; project administration, B.A.D.; resources, J.K.K. and B.V.D.; software, B.A.D. and I.O.B.; validation, B.A.D., A.D.G., J.K.K., and B.V.D.; visualization, B.A.D. and Y.V.B.; writing - original draft, B.A.D., A.D.G., B.V.D., and Y.V.B. All authors have read and agreed to the published version of the manuscript.

Funding: The reported study was funded by RFBR, project number 20-35-70054 «Systems approach to recognition algorithms for seismic hazard assessment».

Acknowledgments: This work employed data provided by the Shared Research Facility «Analytical Geomagnetic Data Center» of the Geophysical Center of RAS (http://ckp.gcras.ru/ access date: 30 July 2021).

Conflicts of Interest: The authors declare no conflict of interest. 


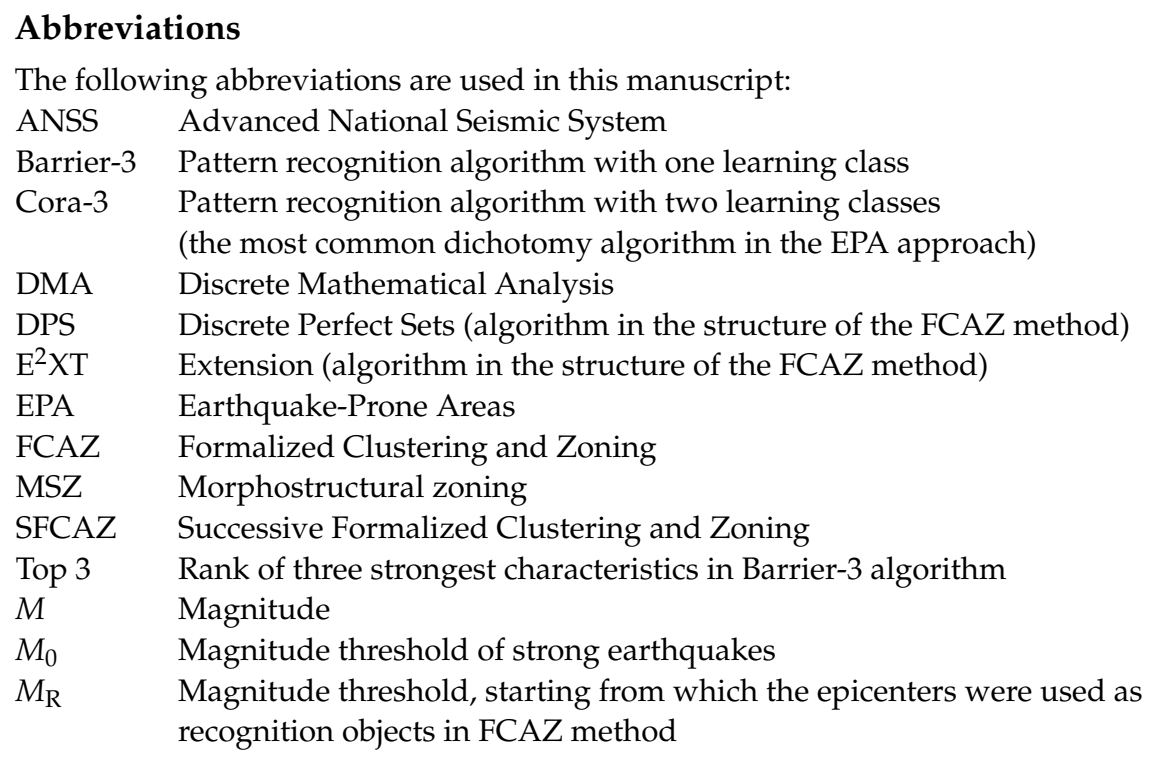

\section{References}

1. Gelfand, I.M.; Guberman, S.; Izvekova, M.L.; Keilis-Borok, V.I.; Ranzman, E.I. Criteria of high seismicity determined by pattern recognition. Tectonophysics 1972, 13, 415-422. [CrossRef]

2. Gelfand, I.M.; Guberman, S.A.; Izvekova, M.L.; Keilis-Borok, V.I.; Rantzman, E.Y. On the criteria of high seismicity. Dokl. Akad. Nauk SSSR 1972, 202, 1317-1320. (In Russian)

3. Gorshkov, A.; Novikova, O. Estimating the validity of the recognition results of earthquake-prone areas using the ArcMap. Acta Geophys. 2018, 66, 843-853. [CrossRef]

4. Gvishiani, A.D.; Gorshkov, A.I.; Rantsman, E.Y.; Cisternas, A.; Soloviev, A.A. In Recognition of Earthquake-Prone Areas in the Regions of Moderate Seismicity; Nauka: Moscow, Russia, 1988; 176p. (In Russian)

5. Gvishiani, A.D.; Soloviev, A.A.; Dzeboev, B.A. Problem of Recognition of Strong-Earthquake-Prone Areas: A State-of-the-Art Review. Izv. Phys. Solid Earth 2020, 56, 1-23. [CrossRef]

6. Kossobokov, V.G.; Soloviev, A.A. Pattern recognition in problems of seismic hazard assessment. Chebyshevskii Sb. 2018, 19, 55-90. (In Russian) [CrossRef]

7. Soloviev, A.A.; Gvishiani, A.D.; Gorshkov, A.I.; Dobrovolsky, M.N.; Novikova, O.V. Recognition of earthquake-prone areas: Methodology and analysis of the results. Izv. Phys. Solid Earth 2014, 50, 151-168. [CrossRef]

8. Alekseevskaya, M.; Gabrielov, A.; Gelfand, I.; Gvishiani, A.; Rantsman, E. Formal morphostructural zoning of mountain territories. Geophysics 1977, 42, 227-233.

9. Gabrielov, A.M.; Gorshkov, V.I.; Rantsman, E.Y. The experience of morphostructural zoning based on formalized features. In Recognition and Spectral Analysis in Seismology, 10 of Computational Seismology; Keilis-Borok, V.I., Ed.; Nauka: Moscow, Russia, 1977; pp. 50-58. (In Russian)

10. Gorshkov, A.I.; Soloviev, A.A.; Zharkikh, Y.I. A Morphostructural Zoning of the Mountainous Crimea and the Possible Locations of Future Earthquakes. J. Volcanol. Seismol. 2017, 11, 407-412. [CrossRef]

11. Rantsman, E.Y. Locations of Earthquakes and Morphological Structure of Mountain Countries; Nauka: Moscow, Russia, 1979; 172p. (In Russian)

12. Rantsman, E.Y.; Glasko, M.P. Morphostructural Nodes are Locations of Extreme Natural Phenomena; Media-Press: Moscow, Russia, 2004; 224p. (In Russian)

13. Gvishiani, A.D.; Agayan, S.M.; Dzeboev, B.A.; Belov, I.O. Recognition of Strong Earthquake-Prone Areas with a Single Learning Class. Dokl. Earth Sci. 2017, 474, 546-551. [CrossRef]

14. Gvishiani, A.D.; Gurvich, V.A. Dynamical Problems of Classification and Convex Programming: Applications; Nauka: Moscow, Russia, 1992; 360p. (In Russian)

15. Gvishiani, A.D.; Gurvich, V.A. Time stability of a prediction of sites of strong earthquakes: II. The eastern part of Central Asia. Izv. Phys. Solid Earth 1983, 18, 665-671.

16. Dzeboev, B.A.; Gvishiani, A.D.; Belov, I.O.; Agayan, S.M.; Tatarinov, V.N.; Barykina, Y.V. Strong Earthquake-Prone Areas Recognition Based on an Algorithm with a Single Pure Training Class: I. Altai-Sayan-Baikal Region, M $\geq 6.0$. Izv. Phys. Solid Earth 2019, 55, 563-575. [CrossRef]

17. Dzeboev, B.A.; Soloviev, A.A.; Dzeranov, B.V.; Karapetyan, J.K.; Sergeeva, N.A. Strong earthquake-prone areas recognition based on the algorithm with a single pure training class. II. Caucasus, $M \geq 6.0$. Variable EPA method. Russ. J. Earth Sci. 2019, 19, ES6005. [CrossRef] 
18. Gvishiani, A.D.; Soloviev, A.A. On the concentration of major earthquakes round the interactions of morphostructural lineaments in South America. In Computational Seismology, 13: Interpretation of Seismological Data: Methods and Algorithms; Keilis-Borok, V.I., Levshin, A.L., Eds.; Allerton: New York, NY, USA, 1981; pp. 42-48.

19. Soloviev, A.A.; Krasnoperov, R.I.; Nikolov, B.P.; Zharkikh, J.I.; Agayan, S.M. Web-Oriented Software System for Analysis of Spatial Geophysical Data Using Geoinformatics Methods. Izv. Atmos. Ocean Phys. 2018, 54, 1312-1319. [CrossRef]

20. Soloviev, A.A.; Gvishiani, A.D.; Nikolov, B.P.; Nikolova, Y.I. GIS-Oriented Database on Seismic Hazard Assessment for Caucasian and Crimean Regions. Izv. Atmos. Ocean Phys. 2018, 54, 1363-1373. [CrossRef]

21. Gvishiani, A.D.; Dzeboev, B.A.; Agayan, S.M. FCAZm intelligent recognition system for locating areas prone to strong earthquakes in the Andean and Caucasian mountain belts. Izv. Phys. Solid Earth 2016, 52, 461-491. [CrossRef]

22. Gvishiani, A.; Dzeboev, B.; Agayan, S. A new approach to recognition of the earthquake-prone areas in the Caucasus. Izv. Phys. Solid Earth 2013, 49, 747-766. [CrossRef]

23. Agayan, S.M.; Bogoutdinov, S.R.; Gvishiani, A.D.; Kagan, A.I. Smoothing of time series by the methods of discrete mathematical analysis. Russ. J. Earth Sci. 2010, 11, RE40001. [CrossRef]

24. Agayan, S.M.; Bogoutdinov, S.R.; Krasnoperov, R.I. Short introduction into DMA. Russ. J. Earth Sci. 2018, 18, ES2001. [CrossRef]

25. Agayan, S.M.; Tatarinov, V.N.; Gvishiani, A.D.; Bogoutdinov, S.R.; Belov, I.O. FDPS algorithm in stability assessment of the Earth's crust structural tectonic blocks. Russ. J. Earth Sci. 2020, 20, ES6014. [CrossRef]

26. Bogoutdinov, S.R.; Agayan, S.M.; Gvishiani, A.D.; Graeva, E.M.; Rodkin, M.V.; Zlotnicki, J.; Le Mouel, J.L. Fuzzy logic algorithms in the analysis of electrotelluric data with reference to monitoring of volcanic activity. Izv. Phys. Solid Earth 2007, 43, 597-609. [CrossRef]

27. Gvishiani, A.D.; Agayan, S.M.; Bogoutdinov, S.R. Discrete mathematical analysis and monitoring of volcanoes. Inzhenernaya Ekol. 2008, 5, 26-31. (In Russian)

28. Gvishiani, A.D.; Agayan, S.M.; Bogoutdinov, S.R. Mathematical Methods of Geoinformatics. I. A New Approach to Clusterization. Cybern. Syst. Anal. 2002, 38, 238-254. [CrossRef]

29. Gvishiani, A.D.; Agayan, S.M.; Bogoutdinov, S.R.; Soloviev, A.A. Discrete mathematical analysis and applications in geology and geophysics. Vestn. Kamchatskoi Reg. Organ. Uchebno-Nauchnyi Tsentr. Seriya: Nauk. O Zemle 2010, 2, 109-125. (In Russian)

30. Soloviev, A.A.; Agayan, S.M.; Gvishiani, A.D.; Bogoutdinov, S.R.; Chulliat, A. Recognition of disturbances with specified morphology in time series: Part 2. Spikes on 1-s magnetograms. Izv. Phys. Solid Earth 2012, 48, 395-409. [CrossRef]

31. Agayan, S.; Soloviev, A. Recognition of dense areas in metric spaces basing on crystallization. Syst. Res. Inf. Technol. 2004, 2, 7-23.

32. Agayan, S.M.; Bogoutdinov, S.R.; Dobrovolsky, M.N. Discrete perfect sets and their application in cluster analysis. Cybern. Syst. Anal. 2014, 50, 176-190. [CrossRef]

33. Dzeboev, B.A. A New Approach to Monitoring Seismic Activity: California Case Study. Dokl. Earth Sci. 2017, 473, 338-341. [CrossRef]

34. Dzeboev, B.A.; Krasnoperov, R.I. On the monitoring of seismic activity using the algorithms of discrete mathematical analysis. Russ. J. Earth Sci. 2018, 18, ES3003. [CrossRef]

35. Gvishiani, A.D.; Dzeboev, B.A.; Belov, I.O.; Sergeyeva, N.A.; Vavilin, E.V. Successive Recognition of Significant and Strong Earthquake-Prone Areas: The Baikal-Transbaikal Region. Dokl. Earth Sci. 2017, 477, 1488-1493. [CrossRef]

36. Gorshkov, A.I.; Soloviev, A.A. Recognition of earthquake-prone areas in the Altai-Sayan-Baikal region based on the morphostructural zoning. Russ. J. Earth Sci. 2021, 21, ES1005. [CrossRef]

37. Gorshkov, A.I.; Soloviev, A.A.; Zharkikh, J.I. Recognition of Strong Earthquake Prone Areas in the Altai-Sayan-Baikal Region. Dokl. Earth Sci. 2018, 479, 412-414. [CrossRef]

38. Bongard, M.M. Recognition Problem; Nauka: Moscow, Russia, 1967; 320p. (In Russian)

39. Bongard, M.M.; Vaintsvaig, M.N.; Guberman, S.A.; Izvekova, M.L.; Smirnov, M.S. Using a learning program for identifying oil reservoirs. Geol. I Geofiz. 1966, 2, 15-29. (In Russian)

40. Soloviev, A.A.; Novikova, O.V.; Gorshkov, A.I.; Piotrovskaya, E.P. Recognition of potential sources of strong earthquakes in the Caucasus region using GIS technologies. Dokl. Earth Sci. 2013, 450, 658-660. [CrossRef]

41. Soloviev, A.A.; Gorshkov, A.I.; Soloviev, A.A. Application of the data on the lithospheric magnetic anomalies in the problem of recognizing the earthquake prone areas. Izv. Phys. Solid Earth 2016, 52, 803-809. [CrossRef]

42. Shebalin, N.V.; Tatevosian, R.E. Catalogue of large historical earthquakes of the Caucasus. In Historical and prehistorical earthquakes in the Caucasus; Giordini, D., Balassanian, S., Eds.; NATO ASI Series, 2. Enviroment-Vol. 28; Kluwer Academic Publishers: Dordrecht, The Netherlands; Boston, MA, USA; London, UK, 1997; pp. 201-232.

43. Karapetyan, J.K.; Sargsyan, R.S.; Kazaryan, K.S.; Dzeranov, B.V.; Dzeboev, B.A.; Karapetyan, R.K. Current state of exploration and actual problems of tectonics, seismology and seismotectonics of Armenia. Russ. J. Earth Sci. 2020, 20, ES2005. [CrossRef]

44. Zadeh, L.A. Fuzzy sets. Inf. Control 1965, 8, 338-353. [CrossRef]

45. Gvishiani, A.D.; Dzeboev, B.A.; Agayan, S.M.; Belov, I.O.; Nikolova, J.I. Fuzzy Sets of High Seismicity Intersections of Morphostructural Lineaments in the Caucasus and in the Altai-Sayan-Baikal Region. J. Volcanol. Seismol. 2021, 15, 73-79. [CrossRef]

46. Reasenberg, P. Second-order moment of central California seismicity, 1969-82. J. Geophys. Res. 1985, 90, 5479-5495. [CrossRef]

47. Zaliapin, I.; Ben-Zion, Y. Earthquake clusters in southern California I: Identification and stability. J. Geophys. Res. Solid Earth 2013, 118, 2847-2864. [CrossRef] 
48. Zaliapin, I.; Gabrielov, A.; Keilis-Borok, V.; Wong, H. Clustering analysis of seismicity and aftershock identification. Phys. Rev. Lett. 2008, 101, 018501. [CrossRef]

49. Abubakirov, I.R.; Gusev, A.A.; Guseva, E.M.; Pavlov, V.M.; Skorkina, A.A. Mass determination of moment magnitudes $M_{\mathrm{w}}$ and establishing the relationship between $M_{\mathrm{W}}$ and $M_{\mathrm{L}}$ for moderate and small Kamchatka earthquakes. Izv. Phys. Solid Earth 2018, 54, 33-47. [CrossRef]

50. Dzeboev, B.A.; Agayan, S.M.; Zharkikh, Y.I.; Krasnoperov, R.I.; Barykina, Y.V. Strongest Earthquake-Prone Areas in Kamchatka. Izv. Phys. Solid Earth 2018, 54, 284-291. [CrossRef]

51. Skorkina, A.A. Scaling of two corner frequencies of source spectra for earthquakes of the Bering fault. Russ. J. Earth Sci. 2020, 20, ES2001. [CrossRef]

52. Kondorskaya, N.V.; Shebalin, N.V.; Khrometskaya, Y.A.; Gvishiani, A.D. New Catalog of Strong Earthquakes in the USSR from Ancient Times through 1977; World Data Center A for Solid Earth Geophysics, Report SE-31; NOAA: Boulder, CO, USA, 1982; 608p.

53. Fedotov, S.A.; Solomatin, A.V. The long-term earthquake forecast for the Kuril-Kamchatka island arc for the September 2013 to August 2018 period; the seismicity of the arc during preceding deep-focus earthquakes in the sea of Okhotsk (in 2008, 2012, and 2013 at $M=7.7,7.7$, and 8.3). J. Volcanol. Seismol. 2015, 9, 65-80. [CrossRef]

54. Dzeboev, B.A.; Krasnoperov, R.I.; Belov, I.O.; Barykina, Y.I.; Vavilin, E.V. Modified algorithmic system FCAZm and strong earthquake-prone areas in California. Geoinformatika 2018, 2, 2-8. (In Russian)

55. Gvishiani, A.; Dobrovolsky, M.; Agayan, S.; Dzeboev, B. Fuzzy-based clustering of epicenters and strong earthquake-prone areas. Environ. Eng. Manag. J. 2013, 12, 1-10. [CrossRef]

56. Gvishiani, A.D.; Agayan, S.M.; Dobrovolsky, M.N.; Dzeboev, B.A. Objective epicenter classification and recognition of strongearthquake-prone areas in California. Geoinformatika 2013, 2, 44-57. (In Russian)

57. Gvishiani, A.D.; Dzeboev, B.A.; Sergeyeva, N.A.; Belov, I.O.; Rybkina, A.I. Significant Earthquake-Prone Areas in the Altai-Sayan Region. Izv. Phys. Solid Earth 2018, 54, 406-414. [CrossRef]

58. Gvishiani, A.D.; Dzeboev, B.A. Assessment of seismic hazard in choosing of a radioactive waste disposal location. Min. J. 2015, 10, 39-43. (In Russian) [CrossRef]

59. Karapetyan, J.K.; Gasparyan, A.S.; Shakhparonyan, S.R.; Karapetyan, R.K. Registration and spectral analysis of waveforms of 10.24.2019 earthquake in the Caucasus using the new IGES-006 seismic sensor. Russ. J. Earth Sci. 2020, 20, ES6006. [CrossRef]

60. Gvishiani, A.D.; Dzeboev, B.A.; Sergeyeva, N.A.; Rybkina, A.I. Formalized Clustering and the Significant Earthquake-Prone Areas in the Crimean Peninsula and Northwest Caucasus. Izv. Phys. Solid Earth 2017, 53, 353-365. [CrossRef]

61. Nekrasova, A.K.; Kossobokov, V.G. Unified scaling law for earthquakes in Crimea and Northern Caucasus. Dokl. Earth Sci. 2016, 470, 1056-1058. [CrossRef]

62. Gelfand, I.M.; Guberman, S.A.; Keilis-Borok, V.I.; Knopoff, L.; Press, F.S.; Ranzman, E.Y.; Rotwain, I.M.; Sadovsky, A.M. Pattern recognition applied to earthquake epicenters in California. Phys. Earth Planet. Inter. 1976, 11, 227-283. [CrossRef]

63. Gvishiani, A.D.; Zhidkov, M.P.; Soloviev, A.A. On transferring the criteria of high seismicity of Andean mountain belt to Kamchatka. Izv. Akad. Nauk SSSR. Fiz. Zemli 1984, 1, 20-33. (In Russian)

64. Gvishiani, A.D.; Zhidkov, M.P.; Soloviev, A.A. Recognition of strong-earthquake-prone areas: X. M 7.75 earthquake prone areas on the Pacific Coast of South America. In Mathematical Models of the Structure of the Earth and the Earthquake Prediction, 14 of Computational Seismology; Keilis-Borok, V.I., Ed.; Allerton: New York, NY, USA, 1983; pp. 56-68.

65. Dzeboev, B.A.; Karapetyan, J.K.; Aronov, G.A.; Dzeranov, B.V.; Kudin, D.V.; Karapetyan, R.K.; Vavilin, E.V. FCAZ-recognition based on declustered earthquake catalogs. Russ. J. Earth Sci. 2020, 20, ES6010. [CrossRef]

66. Zgurovsky, M.Z.; Pankratova, N.D. System Analysis: Theory and Applications; Data and Knowledge in a Changing World; Springer: Berlin/Heidelberg, Germany, 2007; 447p. [CrossRef]

67. Cisternas, A.; Godefroy, P.; Gvishiani, A.; Gorshkov, A.; Kossobokov, V.; Lambert, M.; Ranzman, E.; Sallantin, J.; Saldano, H.; Soloviev, A.; et al. A dual approach to recognition of earthquake prone areas in the Western Alps. Ann. Geophys. 1985, 3, 249-270.

68. Gorshkov, A.; Kossobokov, V.; Soloviev, A. Recognition of earthquake-prone areas. In Nonlinear Dynamics of the Lithosphere and Earthquake Prediction; Keilis-Borok, V., Soloviev, A., Eds.; Springer: Heidelberg, Germany, 2003; pp. 239-310. [CrossRef]

69. Gorshkov, A.I.; Kuznetsov, I.V.; Soloviev, A.A.; Panza, G.F. Identification of future earthquake sources in the Carpatho-Balkan orogenic belt using morphostuctural criteria. Pure Appl. Geophys. 2000, 157, 79-95. [CrossRef]

70. Gorshkov, A.I.; Panza, G.F.; Soloviev, A.A.; Aoudia, A. Morphostructural zonation and preliminary recognition of seismogenic nodes around the Adria margin in peninsular Italy and Sicily. J. Seismol. Earthq. Eng. 2002, 4, 1-24. 